\title{
Die sanktionistische Theorie des Sollens
}

\section{Gottfried Seebaß}

\section{Ein behavioristisches Erbe}

Der Behaviorismus wirft auch nach seinem Niedergang lange Schatten. Der neuzeitlichen Bewußtseinsphilosophie bzw. -psychologie mit ihren vielfältigen Spekulationen und Subjektivismen überdrüssig, aber beflügelt auch von der ldee eines geschlossenen physikalistischen Weltbilds hatte er sich zum Ziel gesetzt, mentale Leistungen durchweg auf behaviorale zurückzuführen. Dazu gehörten auch die Phänomene der Willentlichkeit. Manche Behavioristen wollten sie einfach als sekundäre (,adverbiale') Qualifikationen bzw. charakteristische Formen von (offenbar) zielgerichtetem Verhalten analysieren. Häufiger allerdings war der Rekurs auf Verhaltensdispositionen, da nur diese geeignet erschienen, volitionale Zustände auch losgelöst von aktuellem Verhalten zuzuschreiben und der Vielfalt ihrer behavioralen Manifestationen Genüge zu tun. In der ,Philosophie des Geistes' überlebt dieser Ansatz - modifiziert und erweitert - bis heute (,Funktionalismus'). Fast immer aber bleibt er abstrakt und rein programmatisch. Nicht ohne Grund. Versucht man nämlich zu konkretisieren, was es denn heißen könnte, z.B. einen bestimmten Wunsch oder Willen ausschließlich dadurch zu explizieren, welche behavioralen Wirkungen er unter welchen Bedingungen hat, zeigt sich sehr bald, daß dieses Vorhaben hoffnungslos ist. ${ }^{1}$ Zwar sind Dispositionen unerläßlich, um die Motivationalität und Handlungsbezogenheit des Wollens zu fassen und verständlich zu machen, warum man von volitionalen Zuständen auch reden kann, wenn diese zeitweilig nicht bewußt sind. ${ }^{2}$ Sie manifestieren sich aber keineswegs nur in beobachtbarem Verhalten, sondern auch in diversen mentalen Leistungen, und sind allemal vollkommen ungeeignet, um den Rekurs auf bewußte, intentionale Zustände konzeptionell zu ersetzen.

$\mathrm{Da}$ der radikale und rein behaviorale Dispositionalismus ausscheidet, schließt ein partiell dispositionelles Verständnis bewußter Willensbildung und Handlungskontrolle nicht aus. Daß Menschen unter bestimmten Umständen

1 Für Zustände des Glaubens (Meinens etc.) gilt dies entsprechend. Eingehend demonstriert wird das Scheitern aller behavioral-dispositionellen Explikationswersuche in Seebaß (1993 a) Kap. IV, 3

2 Näheres dazu in Seebaß (1993 a) Kap. IV, 5-6 und S. 297f. Anm. 183. 
z.B. den Wunsch oder Willen zu trinken entwickeln und daß dieser sich unter bestimmten, epistemisch vermittelten Zusatzbedingungen zu einer konkreten Handlungsabsicht verdichtet, ist mühelos kausaldispositionell zu beschreiben. Die Frage ist nur, wie weit dieses Muster trägt. Ist es auch für komplexere, höherstufige und reflektierte Formen der intentionalen Handlungssteuerung konzeptuell angemessen, einschließlich solcher, die sich auf Regeln, Normen oder partikuläre Sollensansprüche stützen?

Der Behaviorismus hat diese Frage bejaht. Regelgeleitetes Handeln war für ihn im Prinzip nichts anderes als eine Form des konditionierten, reaktiven Verhaltens auf der Basis erlernter Dispositionen, die durch äußere oder innere Reize aktualisiert (,ausgelöst ${ }^{\natural}$ ) werden. Modell hierfür war nicht die ,klassische Konditionierung' nach Pawlow, sondern die ,instrumentelle bzw. ,operante Konditionierung' nach Thorndike und Skinner. Sie wurde zunächst an Tieren experimentell untersucht und lerntheoretisch verallgemeinert. Demonstriert wurde etwa, in welcher Weise sich ein Verhalten, das in einer bestimmten Reizsituation zunächst spontan emittiert wird (Betätigung einer Taste innerhalb eines Käfigs), durch wiederholte Hinzufügung ,belohnender oder ,bestrafender' Reize (Futterspende, Elektroschock) frequentativ verstärken oder unterdrücken läßt, resultierend in mehr oder weniger stabilen konditionierten Verhaltensmustern. Sonderlich überraschend war das nicht, war es doch eigentlich nur die systematische Anwendung eines Verfahrens, das Menschen von jeher verwendet haben, wenn sie Tiere mit ,Zuckerbrot und Peitsche' zu einem nützlichen oder circensisch amüsanten Verhalten abrichten wollten.

Auch bei der Sozialisation von Kindern kommt es zur Anwendung. Könnte man daher nicht annehmen, daß es das Grundmuster sozialer Kontrolle überhaupt darstellt oder sogar expliziert, was es heißt, einen Sollensanspruch an andere zu richten bzw. sich durch solche Ansprüche aufgefordert oder verpflichtet zu fühlen? Skinner und andere behavioristisch orientierte Psychologen haben nicht gezögert, Imperative, Gesetze, Normen und Werte bzw. die Unterscheidung von gut und schlecht, richtig und falsch insgesamt auf ihr Schema zurückzuführen. ${ }^{3}$ Aber auch Philosophen waren fasziniert von der Idee, zumindest die handlungsleitende Funktion von Regeln und Normen, wenn nicht gar deren bloßen Begriff oder Bestand, in angehängten positiven und negativen Sanktionen festzumachen. Vielleicht der prominenteste und radikalste von diesen war Wittgenstein. Denn er wollte nicht nur die normativen und imperativischen, sondern alle Formen des regelgeleiteten Sprachgebrauchs auf soziale, sanktionengestützte Lernprozesse zurückführen, die er selbst als ein ,Abrichten` bezeichnet und mit der Konditionierung von Tieren

3 Vgl. Skinner (1953) ch. XXI-XXII; Homans (1961) 39ff., 114ff.; A.W. and C.K. Staats (1964) 292f., $303 \mathrm{ff}$. 
verglichen hat. ${ }^{4}$ Diese Extremposition entsprang der (verfehlten $\left.{ }^{5}\right)$ Annahme, korrigierende oder bekräftigende behaviorale Interaktionen seien unerläßlich, um überhaupt so etwas wie qualitative Standards bzw. Kriterien für ,korrektes' und inkorrektes' Verhalten zu etablieren. Sie braucht uns nicht weiter zu beschäftigen, bleibt aber in ihrer Radikalität beispielhaft und lehrreich auch im Hinblick auf andere, weniger ausgreifende Versuche, Sollensansprüche auf Sanktionen zurückzuführen.

\section{Zwei ,mentalistische" Verfeinerungen}

Manche Lernprozesse beim Menschen folgen dem Modell der sanktionengesteuerten Abrichtung bzw. operanten Konditionierung von Tieren. Doch schon beim Erwerb von elementaren Handlungskompetenzen (Sprechen, Rechnen, Radfahren, Werkzeuggebrauch u.v.a.) spielen Sanktionen, wenn überhaupt, offenkundig nur eine ganz untergeordnete Rolle. Und wo sie bedeutsam sind - wie bei der Entwicklung von Tugenden wie Mut, Ausdauer, Selbstkontrolle, Rücksicht, Hilfsbereitschaft, Aufrichtigkeit u.a. - ist ihre Funktion weitaus komplexer, differenzierter und indirekter, als es das schlichte Konditionierungsmodell nahelegt. Vor allem zwei Verfeinerungen, die den behavioristischen Rahmen sprengen, sind unerläßlich.

2.1 Meist wirken Belohnungen und Bestrafungen nicht direkt auf menschliches Verhalten ein, sondern indirekt, vermittelt durch bewußte Überlegung und Planung. In rudimentärer Form dürfte dies schon für Tiere gelten, ${ }^{6}$ auch

4 Vgl. speziell zu letzterem Wittgenstein (1984) Bd. 5, 131; Bd. 6, 394. Die Rede vom „Abrichten" durchzieht verschiedene Schriften, ganz besonders die Philosophischen Untersuchungen (von $\$ 5$ f. an, sehr prägnant z.B. $\$ 198$ und $\$ 206$ ).

5 Ein Hauptfehler besteht bereits in der Nichtbeachtung der Tatsache, daß schon die Identifizierung kritisierbarer Typen von sprachlichen Äußerungen sowie des relevanten Kritik-oder Bekräftigungsverhaltens selbst qualitative Standards voraussetzt, die es der Theorie nach noch gar nicht geben soll. Näheres zur Kritik bei Seebaß (1981) Kap. XI.

6 Für Tolmans Ratten, die lernten, eine Futterbelohnung auch auf verschlungenen Pfaden zielstrebig anzusteuern, ist das eher zweifelhaft, gleichgültig ob man seine behavioralen Explikationen mentalistischer Termini wie "Ziel", "Zweck", "Zweck-Mittel-Erwartung", „Kognition" u.a. für sinnvoll hält oder nur für eine weitere, schlagende Demonstration des irreduzibel projektiven Charakters aller mentalen Zuschreibungen (vgl. Tolman 1932; ders., 1951, ch. 4-6, 19). Doch die diversen relevanten Untersuchungen an Primaten, die W. Köhler ( 1973 ) und B. Rensch (1973) durchgeführt haben, legen die Annahme nahe, daß wir es hier bereits mit einer Form oder Vorform bewußten, sanktionsorientiert planenden Uberlegens zu tun haben. Vor allem die Experimente Renschs (a.a.O., Kap. 5), bei denen nach einer längeren Phase der tatenlosen, offenbar rein ,gedanklichen "Vorbereitung ein zügiges Problemlösungsverhalten mit (erwartet) belohnender Folge auftrat, liefern ein starkes Indiz für bewußte Handlungsplanung. 
wenn von genuinen, intentionalen Zuständen des Wollens und Meinens oder von rationalen Schlußprozessen (womöglich sogar in sprachlicher oder sprachanaloger Form) hier kaum die Rede sein kann. Beim Menschen aber sind sie die Regel, auch bei der Handlungssteuerung mit Sanktionen. Wir wissen eben, daß wir auf bestimmte Handlungen Lohn oder Strafe zu gewärtigen haben, und stellen unsere Willensbildung prospektiv darauf ein. In simplen Fällen geschieht das rasch und fast automatisch, in weniger simplen erst über längere Überlegungen, die prinzipiell ergebnis- und entscheidungsoffen sind. Wer Sollensansprüche an Menschen sanktionistisch erklären will, sollte sich also nicht (wie der behavioristische Konditionalist) mit dem bloßen Faktum positiver und negativer Folgen begnügen, die zur Verhaltenskontrolle angehängt werden, sondern sein Modell entsprechend verfeinern. Dennoch kann er behaupten, daß das Sollen sich in der Einführung geeigneter Folgen und im Wissen darum erschöpft. Losgelöst von den behavioristischen Simplifizierungen, d.h. unter Anerkennung der Tatsache, daß der Einfluß von Sanktionen normalerweise kein direkter und (quasi-) kausalgesetzlicher ist, sondern ein rational bzw. dianoetisch vermittelter und offener, kann der Sanktionist also durchaus am Schema von, Zuckerbrot und Peitsche' festhalten.

2.2 Mentale Prozesse kommen aber nicht nur bei der Vermittlung zwischen Sanktion und Verhalten ins Spiel, sondern auch bei der Sanktionierung selbst. Schon das behavioristische Konditionierungsmodell wirft ja die theoretische Frage auf, ob als ,Bekräftiger' oder ,Bestrafer' tatsächlich die angehängten äußeren Reize (Futterspende, Elektroschock) gelten können oder vielmehr nur die durch sie hervorgerufenen inneren Lust- und Schmerzempfindungen, von denen sich dann sogar annehmen läßt, daß sie nach der Lernphase, bedingt durch klassische Pawlowsche Konditionierung, direkt vom primären Reiz (Drucktaste) ausgelöst werden und das appetitive bzw. aversive Verhalten verursachen. Für konsequente Behavioristen ist diese ,mentalistische Wendung natürlich tabu bzw. muß durch anschließende Reduktion auch von Lust und Schmerz auf geeignete physiologistische, hypothetische Konstrukte oder gar rein behaviorale, intervenierende Variablen' baldmöglichst überholt werden. ${ }^{7}$ Andere Theoretiker aber sind nicht gehindert, $b$, wußte Gefühle der Lust und Unlust als die (zumindest im menschlichen No nalfall) ausschlaggebenden Faktoren anzuerkennen, die durch externe sanktionen hervorgerufen bzw. als Folgen sanktionierter Handlungen antizipıert und bei der Willensbildung berücksichtigt werden.

Mehr noch. Körperliche Lust und Unlust, die bei der Abrichtung von Tieren im Vordergrund stehen, spielen bei Menschen nur eine begrenzte Rolle. Nahrungsentzug und Prügelstrafen im Recht sind einschlägig, Geldstrafen

7 Zur Terminologie vgl. MacCorquodale / Meehl (1948). 
und Gefängnisstrafen dagegen nicht. Sie wirken vor allem durch Freibeitsbeschränkungen, die sich primär beim frustrierten Wünschen und Wollen selbst und nur sekundär, wenn überhaupt, in Unlustgefühlen zeigen und dann größtenteils auch nicht in körperlichen. Zudem wirken sie durch soziale Ächtung, die noch stärker ins Gewicht fällt, wenn nicht rechtsförmige soziale Normen durchgesetzt werden: bestehende Schönheitsideale, Ansprüche der Mode oder des Lebensstils, gruppenspezifische Verhaltenskodizes, Spielregeln, Regeln des Takts und der Etikette, universale moralische Normen, aber auch technische Regeln und Kunstregeln, sofern deren Befolgung wesentlich ist für den sozialen Status, den die Betroffenen innerhalb ihrer Gruppe oder Institution genießen. ${ }^{8}$ Soziale Ächtung und Anerkennung wirken weniger über Lust und Unlust im engeren Sinne, wohl aber über Gefühle anderer Art. Ein Mensch, der geltenden sozialen Standards nicht entspricht und deshalb ausgegrenzt wird, wird darauf je nach Art und Umständen z.B. mit Gefühlen von Schuld, Scham und Schande, Erniedrigung, Niedergeschlagenheit, Selbstwertverlust oder Verzweiflung reagieren und diese Reaktionen später genauso antizipieren und seiner Willensbildung zugrundelegen wie den Vollzug der Ausgrenzung selbst. Letztere kann sogar ganz entfallen. Denn sind die Standards erst einmal ,verinnerlicht" und Teil der eigenen Person (wie beim "Ich-Ideal" oder "Über-Ich" Freuds), werden die zunächst extern induzierten, sanktionierenden Gefühle zu internen Sanktionen, die bei der Willensbildung entweder als (z.B.) erwartbare ,Gewissensbisse' antizipiert oder schon präsent wirksam werden als Begleiterscheinungen von Wünschen und Absichten, bei denen sich ,das Gewissen regt'. All dies gilt, mutatis mutandis, natürlich auch für die entsprechenden Positivvarianten, z.B. ,gutes Gewissen" bei erwartbarer sozialer Anerkennung, und nicht nur für moralische oder moralähnliche Normen, sondern für alle Standards, die Gegenstand sozialer Anerkennung und Ächtung werden können. ${ }^{9}$

8 Die Inkompetenz eines Mechanikers oder Mannschaftssportlers z.B. kann leicht dazu führen, daß er von seinen Teamkollegen verachtet oder geschnitten wird, also insofern negativ sanktioniert. Ein relevantes Beispiel aus dem Bereich der Kunst liefert eine Anekdote über J.S. Bach, nach der dieser einen seiner Söhne nicht nur getadelt, sondern sogar geohrfeigt haben soll, als er sein Klavierspiel beendete, ohne mit einer regelrechten Kadenz geschlossen zu haben.

9 Ein Mensch, der sein Selbstwertgefühl daran festmacht, stets ,up to date zu sein, kann durch aufkommende Schuld- und Schamgefühle z.B. innerlich genötigt werden, ein unmodernes Kleidungsstück nicht zu kaufen, obwohl es ihm gefällt, oder als Wissenschaftler einen Denkstil bzw. Gedankengang nur deshalb fallen zu lassen, weil er weiß oder befürchtet, daß seine Kollegen die Nase rümpfen. Auch die sprichwörtliche ,Schere im Kopf" von Politikern und politisch gebundenen Journalisten funktioniert, wenn sie erst einmal da ist, über solche inneren Sanktionen. Eine perfide Werbung der 1980er Jahre versuchte sogar (fraglos gestützt auf einschlägige Marktforschung) zu insinuieren, Hausfrauen müßten sich, ein Gewissen machen', wenn sie einen gewissen Weichspüler nicht verwendeten. Daß sich ein normaler 
Wer soziales Sollen sanktionistisch erklären will, muß also und sollte keineswegs nur auf äußere Sanktionen Bezug nehmen. So ist der (schon in der Antike entwickelte und vielfach aufgegriffene ${ }^{10}$ ) Gedanke, Gefühle von Schuld und Scham, die sozialer Ächtung korrespondieren und intern sanktionierend sind, seien konstitutiv für die Moral, ansatzweise bereits von Bentham ${ }^{11}$ und neuerlich vor allem von Tugendhat ${ }^{12}$ sanktionistisch gewendet worden. Ein praktisches Müssen, so Tugendhat mit dem Anspruch auf eine „begriffliche Notwendigkeit", sei „überhaupt nur zu verstehen auf der Basis einer Sanktion, die eintritt, wenn ihr zuwidergehandelt wird“, was beim moralischen Müssen eben die Scham bzw. das Schuldgefühl der Betroffenen seien, korrespondierend zur Geringschätzung oder Empörung der anderen. ${ }^{13}$ Tugendhat steht damit nicht allein. Das prinzipiell gleiche Konzept findet sich, von ihm wohl unbemerkt, schon bei Skinner, verbunden hier natürlich mit dem (uneingelösten) Programm, auch Scham und Schuld, wie alle Gefühle, letztlich behavioristisch reduzieren zu können. ${ }^{14}$ Bei allen Differenzen in dieser und vielen anderen Hinsichten ist die konzeptionelle Parallele doch augenfällig. Die Rolle, die Scham und Schuld bei der Konstitution von Moral spielen sollen, ist bei beiden Autoren im Kern die gleiche, d.h. sie folgt dem Modell der operanten Konditionierung bzw. der Abrichtung von Tieren mit ,Zuckerbrot und Peitsche‘. Moralisch gefordert zu sein, soll beidemal nichts anderes heißen, als dem erwartbaren oder schon aktuellen Druck ausgesetzt zu sein, der von der Gemeinschaft (als ,Dompteur') ausgeht. Wenn diese sich keiner äußeren, son-

Journalist, Techniker oder Sportler auch dann für seine Fehler schämen und ,innerlich zur Ordnung rufen' wird, wenn er sicher sein kann, daß andere es nicht bemerken, ist eher zweifelhaft. Nicht implausibel aber erscheint die Annahme, daß sich nach absolvierter, extern sanktionenbewehrter Musikerziehung bei Bachs Sohn (Anm. 8) später auch in Abwesenheit seines Vaters das ,musikalische Gewissen' regte, wenn er versucht war, unkadenziert sein Spiel zu enden.

10 Vgl. Platon: Nomoi 646e10-647b1; Aristoteles: Nikomachische Ethik 1116a27-32; Rhetorik, II, 6. Diverse Belege aus dem römischen Recht findet man zustimmend zitiert bei S. Pufendorf: De jure naturae et gentium, I, 6,14. Jüngere Beispiele sind (u.a.) Mill (1969) 228f., 231f., und Hart (1961) 84, $175 f$.

11 Bentham (1970) 47, 105f. Zu Benthams Sanktionismus, der an diesen Stellen nicht explizit ist, vgl. ausführlich Hacker (1973) $135 \mathrm{ff}$.

12 Tugendhat (1984) 73-75, 133f., 140f.; (1993) 19, 43-48, 59f., 236-238; (1997) 11, 14, 33, $37,40,56,87,103 \mathrm{f} ., 129 ;(2001) 8,164$.

13 Vgl. Tugendhat (1993) 48, 59f.; (1997) 103, 126. Tugendhat verkennt nicht, daß interne Sanktionen wie Scham oder Schuldgefühl auch bei nichtmoralischen sozialen Normen oder Sollensansprüchen auftreten (vgl. 1993, 56f., 237; 1997, 87ff., 112, 126ff.), glaubt aber, eine besondere Klasse solcher Gefühle als spezifisch moralische auszeichnen zu können. Ich halte diese Abgrenzung für zweifelhaft, zumindest aber nicht scharf. Doch kann dies im gegenwärtigen Zusammenhang offen bleiben.

14 Vgl. speziell Skinner (1953) 187f., 324f., 337. Das generelle Programm zur behavioralen Explikation von Gefühlen hat Skinner in ch. X skizziert. 
dern nur einer ,inneren Peitsche" bedient und sich an überlegt und willentlich handlungsfähige, partiell entscheidungsfreie Individuen richtet, ${ }^{15}$ ist dies zwar eine bedeutende Verfeinerung, aber keine konzeptionelle Veränderung des sanktionistischen Grundmodells. Und die disziplinierende Wirkung interner Sanktionen kann u.U. bekanntlich ebenso massiv und dressurähnlich sein wie die von äußeren, oder sie sogar noch übersteigen. ${ }^{16}$

\section{Formen des Sanktionismus}

Als ,Sanktionismus' im weitesten Sinne kann man die These bezeichnen, daß Sollensansprüche notwendig mit Sanktionen verbunden sind. Das allerdings kann verschiedenes heißen. Je nachdem, was man unter "Sollen" und "Sanktion" versteht, ergeben sich inhaltlich variierende Konzeptionen. Wichtiger aber noch ist eine formale Differenzierung, die nicht an speziellere Sanktionsund Sollensbegriffe gebunden ist. Drei Formen des Sanktionismus sind strikt auseinanderzuhalten.

15 Psychologische Reflextheoretiker haben natürlich Mühe, die Phänomene des überlegten, willensgetragenen Handelns in ihr Modell zu integrieren. Auch Skinner (1953, ch. VII; 1974, ch. IV) will darauf nicht ganz verzichten, obwoht er die Idee einer nicht reflexhaften treien Wahl für illusionär hält. Umgekehrt beschreibt Tugendhat $(1976,110 \mathrm{f}$ ) die Wirkung negativer Sanktionen manchmal so, daß der Eindruck entsteht, als wolle er die Möglichkeit einer freien Wahl auf seiten der Adressaten bestreiten.

16 Das wird z.T. bestritten, etwa von Stemmer (2000) 171ff. Doch Stemmer stellt nur auf die unzureichende Abschreckungswirkung interner Sanktionen bei prudentiell-rationalen Egoisten (moralischen Skeptikern") ab, die sich tollständig emanzipiert und auch personal ("als Subjekt", a.a.O., 175) von der Gemeinschaft distanziert haben. Für solche Individuen gilt sein Verdikt. Ein Nietzschescher Zarathustra ist zweifellos gegen Gewissensbisse, Schuldgefühle und Scham immun. Ein solcher aber ist kein realer Menscb, sondern das Kunstprodukt eines outrierten Philosophen, ein "Ubermensch" eben. Daß alle Menschen partiell auch Distanzierungstendenzen haben und daß diese bei sozialisatorisch auRergewöbnlich Deprivierten oder abnorm Veranlagten persönlichkeitsprägend werden können, steht dem nicht entgegen, sondern hestätigt den Regelfall. Wo immer die Sozialisation nomal verläuft, ist die Tatsache, daß „eine Person sich als ein soziales Wesen versteht“, jedenfalls keine Sache von bloßen "Präferenzen, Idealen und Selbstkonzeptionen, die man haben kann, aber nicht haben muß (a.a.O., 174), sondern Teil unseres Selbstverständnisses als Menschen. Mit kritiklosem Konformismus, Traditionalismus, supererogatorischem Altruismus, moralischen Idealen oder dominanter moralischer Motiviertheit hat das nichts zu tun. Zudem behalten wir normalerweise eine Wahlmöglichkeit auch gegenüber sozialen Sollensansprüchen, die wir uns selbst zu eigen gemacht haben und die mit Sanktionen verbunden sind, inneren genauso wie äußeren. Doch so wie es Formen abnormer Distanziertheit von der Gemeinschaft gibt, so gibt es auch Formen abnormer sozialisatorischer Vereinnabmung. Und in diesem Fall kann die Wirkung interner Sanktionen offensichtlich ebenso massiv, dressurähnlich und reflexhaft werden wie die von drakonischen äußeren Strafen, mit denen man Menschen wie Tiere abrichtet. 
3.1 Die erste und schwächste Form ist der ,motivationale Sanktionismus'. Danach sind Sanktionen nur erforderlich, um Sollensansprüche handlungswirksam werden zu lassen, und dies wiederum in zwei verschiedenen Versionen. In einer stärkeren Version haben Sollensansprüche ohne Sanktionen keinerlei Motivationskraft. Diese Auffassung findet man historisch etwa bei Hobbes, ${ }^{17}$ Pufendor $f^{18}$ oder Locke. Letzterer hat z.B. erklärt, die Aufstellung eines Gesetzes ohne Strafen oder Belohnungen sei müßig („frustra“) und völlig vergeblich, („utterly in vain“), da es dann nicht die Kraft eines Gesetzes habe ("has not the Force of a Law“). ${ }^{19}$ Damit ist nicht gesagt, daß es Gesetze, geschweige denn schwächere Formen des Sollens, ohne Sanktionen nicht geben kann. Im Gegenteil, die Rede von der, Vergeblichkeit' setzt ihre Existenz selbst voraus. Aber Locke meint offenbar, ähnlich wie Hobbes und Pufendorf, daß zumindest gesetzesförmige Normen, die nicht sanktionengestützt sind, motivational derart bedeutungslos wären, daß man es genausogut lassen könnte, sie überhaupt aufzustellen. ${ }^{20}$ Sehr realistisch ist diese Diagnose nicht. Sie paßt

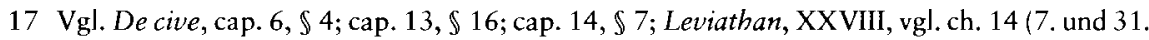
Absatz). Hobbes bestimmt den primären Strafzweck ausdrücklich motivational, nämlich als Förderung bzw. hinreichende Sicherstellung des Gehorsams gegenüber den Gesetzen, erreichbar durch (abschreckende) Einwirkung auf den Willen. Notwendig sei diese, weil Menschen, schlecht gesinnt wie sie nun einmal sind, ohne Strafe erfahrungsgemäß kaum gesetzestreu bleiben würden, so daß ein Gesetz ohne Strafandrohung müßig bzw. vergeblich („frustra“) wäre.

18 Vgl. S. Pufendorf: De officio hominis et civis iuxta legem naturalem, I, 2,7, wo die Strafbewehrung „vollkommener Gesetze“ damit begründet wird, daß das Erlassen bloßer Handlungsvorschriften müßig („supervacuum“) wäre, da der verkehrte menschliche Geist eine Tendenz zum Verbotenen habe („, in vetita tendere“). Die Tatsache, daß Pufendorf, römischer Rechtstradition folgend, auch mit "unvollkommenen Gesetzen“ obne Sanktionen rechnet (dazu: De jure naturae et gentium, I, 6,14), bestätigt den motivationalen Sinn dieses Sanktionismus.

19 J. Locke: Essays on the Law of Nature, ed. W. v. Leyden, Oxford 1954, 172-174; An Essay Concerning Human Understanding I, 3,12 und II, 28, 5-6; The Second Treatise of Civil Government II, 7.

20 So heißt es im Second Treatise XIX, 219: „Where the laws cannot be executed, it is all one as if there were no laws". Ähnlich meint Hobbes (Leviathan, XXVII, 7. Absatz), ein Gesetz ohne Furcht vor folgender Strafe „were not a law, but vain words“. Vergleichbare Aussagen finden sich in der Literatur öfter, vor allem im Kontext der Frage nach der „sozialen Geltung“ von Normen (vgl. unten S. 190, Anm. 61). Wenige davon aber sind tatsächlich motivational sanktionistisch im stärkeren Sinne. So hat v. Wright (1963b, 159; vgl. 191ff. und ders. 1963a, 7, 125-128) z.B. erklärt: „unless there is at least an implicit threat of punishment, i.e. of some evil consequent upon disobedience, then there is properly speaking no command either". Doch was auf den ersten Blick wie eine Neuauflage der Thesen von Hobbes und Locke aussieht, erweist sich bei näherer Prüfung als etwas ganz anderes. Denn erstens ist v. Wright durchaus nicht der Auffassung, daß nur die Sanktionsdrohung motiviert (vgl. Anm. 21). Und zweitens vertritt er überhaupt keinen motivationalen, sondern nur einen auf anspruchsvollere Formen des Sollens beschränkten spezifikatorischen Sanktionismus (s.u. S. 164, Anm. 23). Stärkere motivational sanktionistische Thesen sollte man also mit Vorsicht genießen (selbst die von Locke, vgl. Anm. 22). 
vielleicht auf Menschen, die abnorm unter- oder übersozialisiert sind (Anm. 16), nicht jedoch auf normale Erwachsene. Denn im allgemeinen leben wir nicht in der Vorstellung, sozialen Normen oder anderen Sollensansprüchen, die wir für berechtigt halten, nur deshalb Gewicht zu geben, weil sie extern oder intern sanktioniert sind.

Weit häufiger und prima facie plausibler ist der motivationale Sanktionismus denn auch in einer schwächeren Version, welche die Motivationskraft des Sollens nicht leugnet, aber für unzureichend hält. Auch das ist als generelle Behauptung keineswegs selbstverständlich. Im Gegenteil, welche sozialen Normen so gewichtig sind, daß sie zur Erhöhung der Konformität rechtlich geregelt und strafbewehrt werden sollten und dies in welchem Ausmaß, sind rechtspolitische Fragen, die unterschiedliche Antworten zulassen und historisch wie kulturell wandelbar sind. ${ }^{21}$ Viele zivil- und verwaltungsrechtliche Regelungen etwa (Wirksamkeit eines Testaments, Bestehen eines Garantieanspruchs usw.) sind überhaupt nicht mit einem Bußgeld oder mit Strafen bei Nichterfüllung belegt und wirken dennoch. Im außerrechtlichen Bereich gilt das allemal. Sanktionen, positive wie negative, können die Motivationskraft verstärken und in besonders kritischen Fällen vielleicht auch schaffen. Aber wie weit sie dies tun oder zur Erzielung eines bestimmten Konformitätsgrads tun müssen, ist eine rein empirische Frage. Und die Erfahrung zeigt, daß sie es bei normalen Menschen keineswegs immer tun, geschweige denn, Hobbes oder Locke folgend, immer allein.22 Wie weit der motivationale Sanktionismus im einzelnen reicht, kann nicht die Philosophie, sondern nur die empirische Wissenschaft klären.

21 Schon Aristoteles (Nikomachische Ethik, X,10: 1179b4-16) hat hier differenziert, wenn er die rational vermittelte Einsicht in die Tugend und das bloße Bewußtsein von Scham und Schande zwar bei „freien Menschen" für motivational ausreichend hält, nicht aber bei der "breiten Masse", die der Strafdrohung bedarf, da sie nur durch (niedere) Lust und Unlust motiviert werde. Weiter noch geht eine Auffassung, die in der neueren Literatur öfter vertreten wird, wie z.B. qon v. Wright (1963a) 125f. und Hart (1968) 50. Danach würden die meisten Menschen nicht durch die Strafdrohung, sondern durch Motive anderer Art zur Rechtstreue motiviert, und nur eine kleine "antisoziale Minderheit" bedürfe auch der Furcht vor Strafe. Dies dürfte der Wirklichkeit ziemlich nahekommen.

22 Auch Locke scheint an manchen Stellen, besonders im Second Treatise, so weit nicht gehen zu wollen. Er hält es, anders als Hobbes, ja nicht für ausgemacht, daß der "Naturzustand“ immer ein "Kriegszustand“ ist, sondern meint nur, daß das bloße „Naturgesetz" (das auch aus Vernunft allein, unabhängig von seiner etwaigen Sanktionierung durch Gott, als gültig erkannt werden kann, aber bei fehlendem oder egoistischem Vernunftgebrauch temporär aus dem Blick gerät) nicht genügt, um drohende Übertretungen und die Entwicklung des Naturzustands zum Kriegszustand verläßlich auszuschließen (vgl. II, 5-6; III, 19-29; IX, 124-126). Zudem bedient er sich eines Begriffs der ${ }_{n}$ Strafe", der derart weit gefaßt ist, daß nahezu alle konformitätsfördernden Maßnahmen unter ihn fallen, einschließlich schlichter Wiedergutmachungsleistungen (II, 8. 10-11), so daß der sanktionistische Anspruch überhaupt zweifelhaft wird (Abschnitr 5). 
3.2 Ähnlich steht es mit der zweiten Form, dem, spezifikatorischen Sanktionismus. Auch er behauptet nicht, daß es kein sanktionsunabhängiges Sollen gibt, wohl aber, daß bestimmte Arten des Sollens ohne Sanktionen nicht denkbar sind, und dies nicht nur faktisch bzw. motivational, sondern begrifflich. So wie die Rede vom, Wissen' zwar die vom, Glauben' als begrifflichen Kern enthält, aber (nach klassischer Auffassung) außerdem impliziert, daß der geglaubte Satzgehalt wahr und der Glaube einschlägig begründet ist, so gibt es auch deontische Redeformen, die über den Sollenskern hinaus sanktionistisch spezifiziert sind. Konzeptionell ist das wenig aufregend, teilweise sogar trivial. "Strafgesetze* sind eben per definitionem Gesetze, die strafbewehrt sind, ebenso ,Strafstoß-" und ,Strafzeitregeln" in Sportarten wie Fußball und Eishockey. Nichttrivial wird die These, wenn man sie auf den Gesetzesbegriff insgesamt ausdehnt oder z.B. behauptet, sie gelte für alle Muß-Klauseln (unterschieden von bloßen Soll-Bestimmungen) oder für alle Befehle, moralischen Forderungen und Pflichten (unterschieden von bloßen Ratschlägen, Ermahnungen, Lebensregeln oder supererogatorischen Empfehlungen). ${ }^{23} \mathrm{Als}$ bloße terminologische Regulierungsvorschläge oder stipulative Definitionen innerhalb einer bestimmten Theorie ist auch dagegen wenig einzuwenden. Als Explikationen des gewöhnlichen oder des etablierten philosophischen bzw. wissenschaftlichen Sprachgebrauchs sind sie jedoch begründungsbedürftig.

Wie weit ein so verstandener spezifikatorischer Sanktionismus reicht, ist eine sprachanalytische bzw. empirisch-linguistische und partiell philologische Frage, die für jedes Textkorpus neu zu stellen ist. Sie muß und kann hier offen bleiben. Denn der konzeptuelle Anspruch bleibt ja begrenzt und läßt die Eigenständigkeit des Sollens als Kern unangetastet. Auch die Frage, warum

23 Prominent vertreten wird ein spezifikatorischer Sanktionismus dieses Typs z.B. von dem englischen Rechtstheoretiker J. Austin (1832, 51885$)$ 21-25. 32f. Als Sanktionist lehnt Austin zwar den römischen Begriff des, unvollkommenen Gesetzes“ (Anm. 18) konsequent ab (a.a.O., 32f.), definiert aber den gesetzeskonstituriven Begriff des Befehls („,command", „imperative") und den ihm korrespondierenden Begriff der Verpflichtung ("obligation “, "duty") explizit mit Hilfe von drei Kriterien, von denen das zweite und dritte nur spezifizierend zum zentralen ersten hinzutreten. Ein Befehl nämlich ist für Austin (1) ein Wunsch, den jemand (2) an andere adressiert äußert und (3) mit einer negativen Sanktion für den Fall seiner Nichterfüllung verbindet. Vergleichbare Beispiele aus der neueren Literatur liefern, z.T, in direkter Anknüpfung an Austin, v. Wright (vgl. Anm. 20); Tugendhat (1993) 40ff.; (1997) 104, sowie Stemmer (2000) passim, und in diesem Band. Die letzteren beiden Autoren begnügen sich allerdings nicht mit einem spezifikatorischen Sanktionismus, sondern erheben auch explikativ sanktionistische Ansprüche (vgl. S. 160, Anm. 12-13; S. 166f., Anm. 27; S. 169, Anm. 29; S. 176f, Anm. 43-45; S. 180, Anm. 49; S. 186, Anm. 57).

Obwohl die Auseinandersetzung mit dem spezifikatorischen Sanktionismus nicht Gegenstand dieses Aufsatzes ist, werden sich im folgenden (besonders in den Abschnitten 7-9) auch Hinweise darauf ergeben, daß er in den angesprochenen nichttritialen Versionen unhaltbar ist, wenn man ihn am gewöhnlichen Sprachgebrauch mißt (zur Rede von „Müssen“, „Fordern“ oder „Verpflichtetsein“ speziell z.B. S. 186, Anm. 57 und S. 194, Anm. 68). 
und wie die Sanktion mit dem so spezifizierten Sollen verknüpft wird, bleibt prinzipiell offen. Es kann sich (analog zum Wahrheitskriterium in der klassischen Definition von "Wissen") um eine separierbare Zusatzbedingung handeln, ebenso aber um eine Bedingung, die (analog zum Begründungskriterium) begrifflich aufs Sollen bezogen ist, weil die Sanktionierung dieses voraussetzt. Hier wird man vor allem von den drei klassischen Strafzwecken ausgehen: Vergeltung, Abschreckung, Besserung, wobei die letzteren beiden zeigen, daß der spezifikatorische Sanktionismus in einem motivationalen fundiert sein kann, der den Sanktionen nur eine stützende Funktion zuweist. Doch auch wenn es rein retributive Gesichtspunkte sind, die der sanktionistischen Spezifizierung zugrundeliegen, muß diese das Sollen nicht tangieren, manifest z.B. in der geläufigen Rede davon, daß Normenverletzungen die ,Basis' für verdiente Sanktionen liefern und wegen dieses Verdienstes „bestraft werden sollten". ${ }^{24}$

3.3 Erst die dritte Form des Sanktionismus geht substantiell darüber hinaus. Jetzt sind Sanktionen nicht nur mit Sollensansprüchen (faktisch oder begrifflich) verknüpft, sondern explizieren, was diese überhaupt ausmacht. Man kann deshalb von ,explikativem Sanktionismus' sprechen. Daß jemand eine bestimmte Handlung tun soll oder zu ihr verpflichtet ist, beißt hier nichts anderes, als daß ihre Unterlassung negative Sanktionen nach sich zieht bzw. ihre Ausführung positive. Dies also und nur dies ist die Form, in der das (verfeinerte) Modell von ,Zuckerbrot und Peitsche" auch den begrifflichen Kern des Sollens betrifft und nicht nur sekundäre Qualifikationen. Dabei wiederum sind zwei Versionen zu unterscheiden. In einer radikalen Version sollen alle Arten des Sollens sanktionistisch expliziert werden. Diesen Anspruch muß man erheben, wenn man an einem gemeinsamen Grundbegriff festhalten will. Denkbar sind aber auch moderate Versionen, die den sanktionistischen Explikationsanspruch, unter Verzicht auf konzeptionelle Einheitlichkeit, nur für bestimmte Sollensarten erheben, etwa (über die spezifikatorisch-sanktionistische These hinaus, S. 164 Anm. 23) für alle rechtlichen oder moralischen Pflichten.

Beispielhaft könnte das Strafrecht sein. Das deutsche Strafgesetzbuch enthält bekanntlich keine Imperative, Muß- oder Sollenssätze, sondern formuliert nur, welche Tatbestände mit welchen Strafen zu ahnden sind. Das wird normalerweise nicht reduktionistisch aufgefaßt, sondern als Kurzformel dafür, daß die Verletzung oder Gewährleistung der tatbestandsmäßig erfaßten

24 So z.B. Mill (1969) 245f. und Hart (1961) 88. Wer die Verhängung von Sanktionen selbst zu einer Frage des Sollens oder Nichtsollens macht, kann dieses, Sollen' offenkundig nicht mehr auf das Faktum bestehender Sanktionen gründen, klar herausgearbeitet z.B. bei Sidgwick (71907) $29 f$. 
Rechtsgüter bei Androhung von Strafe verboten bzw. geboten sind. ${ }^{25}$ Man könnte aber auf den Gedanken kommen, mehr als das, was im Gesetzbuch steht, sei in strafrechtlichen Verboten und Geboten auch nicht enthalten. In diesem Sinne hat Hobbes erklärt, die Strafbewehrung gesetzlicher Bestimmungen solle zwar auch (präventiv, vgl. Anm. 17) allen Bürgern bekannt gemacht werden, richte sich eigentlich aber nicht an sie, sondern sei eine Anweisung an die Staatsbeamten, wie sie mit faktischen Rechtsbrechern verfahren sollen. ${ }^{26}$ Hobbes war kein radikaler explikativer Sanktionist. Auch den impliziten Verbotscharakter des reinen, sanktionsunabhängigen Tatbestandsteils von Gesetzen hat er nicht bestritten. Dennoch eröffnet seine Differenzierung die Möglichkeit, den spezifischen Sollensanspruch, den das Strafrecht an alle Bürger richtet, rein sanktionistisch zu explizieren. Kelsen, der Hobbes' Analyse gefolgt ist, hat dies getan und den Verpflichtungscharakter aller Rechtsnormen nur noch aus ihrer Sanktionierung ableiten wollen. ${ }^{27}$

25 Vgl. als Beispiel für viele andere Baumann / Weber ( $\left.{ }^{9} 1985\right)$ 26. Die Auffassung ist weder neu noch auf die deutsche Rechtswissenschaft beschränkt, sondern findet sich klassisch z.B. auch bei Bentham (1970) 302f.

26 Leviathan, XXVI (siebtletzter Absatz), vgl. De cive, cap. 14, $\$ 7$ und $\$ 23$, ähnlich auch Bentham (1970) 302. Schon die Beschreibung Hobbes', die diverse präskriptive Ausdrücke verwendet (einschließlich von „shall“ und "ought“, vgl. Anm. 24), macht deutlich, daß er mit Formen des Sollens rechnet, die nicht sanktionistisch auflösbar sind.

27 Vgl. Kelsen ( $\left.{ }^{2} 1960\right)$ 7, 26, 36f., 43, 55-57, 116-118, 121, 124; (1946) 21, 45, 60f. Kelsens explikativ sanktionistische Tendenzen sind unverkennbar und bilden den Hintergrund auch für andere Versuche, einschlägige Theoreme „der traditionellen Jurisprudenz“" zu verabschieden. So diagnostiziert er (1946, 62-64) einen vermeintlichen Selbstwiderspruch bei Austin, weil er den rein spezifikatorischen Charakter, den dessen Sanktionismus hat (vgl. Anm. 23), systematisch verkennt bzw. überspringt. Entsprechendes gilt für Kelsens Behauptung, Delikte würden dem Täter „nicht darum zugerechnet, weil er frei ist, sondern der Mensch ist frei, weil ihm zugerechnet wird" $\left({ }^{2} 1960,102\right)$, sowie für die pointiert sanktionistische These, die richtige Strafauffassung bestehe nicht „darin, daß eine Handlung oder Unterlassung darum, weil sie ein Unrecht oder Delikt darstellt, mit einem Zwangsakt als Unrechtsfolge verknüpft wird, sondern darin, daß eine Handlung oder Unterlassung ein Unrecht oder Delikt ist, weil sie mit einem Zwangsakt als ihrer Folge verknüft ist" $\left({ }^{2} 1960,117\right)$. Stemmer (2000), 102f,; in diesem Band 47, zitiert diese Passage und ähnliche zustimmend und geht über sie noch hinaus, indem er sie auch auf moralische Normen überträgt, wie unabhängig von Kelsen schon Tugendhat (Anm. 12-13).

Wie weit die drei zitierten Autoren allerdings konsequente Vertreter eines explikativen Sanktionismus sind, ist weniger klar. Kelsen zumindest wird man kaum dazu rechnen können. Denn er bestreitet die Möglichkeit von sanktionslosen, außerrechtlichen Geboten oder Verboten nicht und läßt auch die Etablierung aller konkreten, sanktionskonstituierten Rechtsnormen formal von einer (zu ihr ermächtigenden) „Grundnorm“ abhängen, die anders eingeführt werden muß. Vor allem aber versteht er die Sanktionierung selbst nicht als faktische Koppelung, sondern hält an der üblichen Beschreibung (S. 165, Anm. 24) fest, wonach bestimmte Handlungen sanktioniert werden sollen, und anerkennt ausdrücklich, daß dieses "Sollen“/,ought“ keinen sanktionistischen Sinn haben kann (vgl. ${ }^{2}$ 1960, 4ff., 10, 26, 45f., $59,119,124 ; 1946,35-37,45 f$.). Doch auch bei Tugendhat und Stemmer gibt es diverse 
Hier also zeichnet sich ein Begriff des Sollens ab, der nur dem (verfeinerten) Modell von ,Zuckerbrot und Peitsche' verpflichtet ist. Er ist zunächst auf den rechtlichen Bereich beschränkt und insofern ,moderat'. Prinzipiell aber ließe er sich erweitern ${ }^{28}$ und gegebenenfalls, dem radikalen explikativen Sanktionismus entsprechend, sogar zum Gattungsbegriff erheben. Dies auszuloten, kann nicht die Aufgabe dieses Aufsatzes sein. Er konzentriert sich darauf, kritisch zu prüfen, was die Rückführung von Sollensansprüchen auf Sanktionen beinbaltet und ob es überhaupt möglich ist, sei es auch nur in Teilbereichen, den explikativen Anspruch einzulösen. Da rein motivationale und spezifikato-

Formulierungen, die eher an einen spezifikatorischen (Anm. 23) oder gar rein motivationalen Sanktionismus denken lassen als an einen explikativen. Der Grund für solche Ungereimtheiten liegt nicht nur in mangelnder Klarheit über die Formen des Sanktionismus. Er liegt auch in der Verwendung laxer, inklusiver bzw. undifferenzierter Begriffe der "Sanktion" (wie schon bei Locke, Anm. 22) sowie darin, daß auch diverse andere Differenzierungen unberücksichtigt bleiben, die in den folgenden Abschnitten herausgearbeitet werden. Die damit verbundene Grundsatzkritik kann deshalb auch nur insoweit als eine Kritik an den zitierten Autoren verstanden werden, als diese sich als Anhänger eines explikativen Sanktionismus darstellen.

28 Folgt man der Hobbesschen Idee von Strafgesetzen als Handlungsanweisungen an Beamte, muß der nächste Schritt natürlich darin bestehen, auch deren Verpflichtung zu einer korrekten Strafpraxis sanktionistisch zu explizieren. Auch sie müßßten demnach bei Inkorrektheiten mit strafrechtlichen Konsequenzen, Disziplinarstrafen oder dem Verlust ihres Amtes zu rechnen haben, zu deren korrekter Umsetzung wiederum andere Beamte verpflichtet sind, die sich (ex hypothesi) aber ihrerseits nur an Sanktionserwartungen von seiten anderer ausrichten können. Und so geht es im Prinzip beliebig weiter. Soll kein Regreß entstehen, mußs die Sanktionspraxis irgendwann zirkulär werden, so daß die Beamten sich indirekt selbst sanktionieren.

Ein solches System ist nicht unvorstellbar, aber ersichtlich instabil, wenn die faktische Sanktionspraxis und die auf sie abgestimmten Sanktionserwartungen der einzige Grund für korrektes Verhalten sind. In Staaten mit einer moralisch und rechtlich korrupten Administration, die diesem Modell relativ nahekommen, gibt es auch entsprechende Auflösungstendenzen. Normalerweise dagegen sorgen die Sozialisation (vgl. Anm. 16) und Auswahlverfahren, die sicherstellen, daß nur einschlägig sozialisierte Personen mit exekutiven Aufgaben betraut werden, für eine stabilisierende normative Grundorientierung. Diese ist nicht mehr sanktionistisch auflösbar, so daß sich die Sanktionen auf eine (schwächere, S. 163) motivationale Funktion beschränken. Schon diese Überlegungen zeigen, daß ein radikaler explikativer Sanktionismus in der Durchführung rasch an Grenzen stößt. Doch um des Argumentes willen soll von empirischen, sozialwissenschaftlichen Einwänden wie diesen im folgenden abgesehen werden.

Kelsen, der seine „reine“ Rechtstheorie weitgehend unabhängig von psychologischen oder sozialwissenschaftlichen Rücksichten entwickeln wollte (vgl. z.B. 1946, 24-28, aber auch unten S. 190, Anm. 61), bat den Regreßeinwand allerdings als eine Bedrohung für seinen Ansatz anerkannt und als einen der Grïnde erwähnt $\left({ }^{2} 1960,26,124 f\right.$, Anm.; 1946, 29, 60), die ihn zu einer Rede vom "Sollen" "ought" zwingen, die prinzipiell nicht sanktionistisch zu interpretieren ist (vgl. Anm. 27). 
rische Formen hierfür irrelevant sind, wird von ,Sanktionismust bzw. ,sanktionistisch' im folgenden nur mehr im explikativen Sinne gesprochen.

\section{Das Interesse am Sanktionismus}

Vor Eintritt in die inhaltliche Auseinandersetzung lohnt ein kurzer Blick auf die Interessen, die der Idee zugrundeliegen. Sie sind im Kern die gleichen wie die von reduktionistischen Behavioristen, auch wenn simplistische (behavioral-physikalistische) Ansprüche in der verfeinerten Version wegfallen. Sanktionisten wollen es möglichst einfach haben und möglichst, naturalisiert'. Sie halten sich etwas darauf zugute, daß ihr Konzept und nur ihres, wie sie glauben, normative und andere Arten des Sollens bzw. Müssens frei von ,obskuren“ oder ,metaphysischen' Prämissen verständlich macht. Doch das erweist sich, näher betrachtet, selbst eher als rhetorische Verdunkelung.

4.1 Ein relevantes Argument stellt auf die erwünschte Eliminierung von Sollensansprüchen $a b$, die nicht als (im weitesten Sinne), menschengemacht ${ }^{\star} \mathrm{zu}$ erweisen sind, sondern außermenschliche Grundlagen haben. Dazu gehören alle naturrechtlichen und theonomen Moralvorstellungen, aber auch philosophische Theorien, die Werte und Normen als ontologisch bzw. transzendental ebenso ,unhintergehbar gegeben' darstellen wie die Objekte und Prinzipien theoretischer Erkenntnis. Manchmal wird sogar jedes kategorische Müssen, das sich nicht in ein prudentiell-hypothetisches auflösen läßt, pauschal den Sollensansprüchen zugerechnet, die keinen menschlichen Ursprung haben. Besonders darin zeigen sich gravierende Begriffsverwirrungen (Abschnitt 7). Aber auch wenn man davon vorläufig absieht, erweist sich das Argument als hinfällig. Denn auch wenn jedes Sollen bzw. Müssen menschlich begründet ist und durch Menschen prinzipiell aufhebbar, folgt der Sanktionismus daraus keineswegs notwendig. Dazu bedürfte es offenbar weiterer, starker Zusatzprämissen. Ja, man kann nicht einmal sagen, daß seine Einführung hinreichend oder doch wenigstens bilfreich wäre, um menschliches Sollen zu begründen. Schließlich könnten auch göttliche Gebote (o.a.) als bloße Tatbestandsbeschreibungen mit angehängten Sanktionen aufgefaßt werden. Diese Form der ,Metaphysikfreiheit" ist für den Sanktionismus also bedeutungslos.

4.2 Kaum besser aber steht es mit dem Anspruch auf, naturalistische' ontologische Sparsamkeit. Daß etwas sein soll oder muß, scheint prima facie weniger leicht begreiflich zu sein, als daß es ist und positive oder negative Folgen hat. Doch faktische Folgen genügen nicht. Auf sie könnte sich allenfalls der behavioristische Lerntheoretiker beschränken, der nur Beziehungen zwischen realen vergangenen Stimulationen und präsenten Reaktionen erfassen will. Das verfeinerte Modell aber rekurriert auf bewußte, intentionale Erwartungen und Überlegungen. Sanktionen, mit denen man prospektiv rechnen muß, sind 
jedoch ebenfalls kein Bestandteil der wirklichen Welt, sondern mögliche Satzgehalte bzw. Sachverhalte, die erst wahr bzw. zu Tatsachen werden sollen (vgl. S. 165, Anm. 24), wenn die betreffenden Standards erfüllt sind oder nicht. Ob es dazu überhaupt kommt und, wenn ja, folgerecht sanktioniert wird, bleibt prinzipiell offen. Das gilt zumindest dann, wenn die Sanktionierung, wie üblich, eine Angelegenheit willentlich handelnder Menschen ist und ihr Wille sich nicht vollständig kausaldispositionell auflösen läßt (S. 155f.). Nur wenn man dies bestreiten oder so etwas wie eine universale, nichtintentionale ,Sanktionsmaschinerie erfinden würde, die direkt (ohne intervenierendes Wollen) durch relevantes Verhalten kausal ausgelöst wird, ${ }^{29}$ könnte man sagen, daß der Sanktionismus bestehende Naturalisierungsinteressen befriedigt. Beides aber ist illusionär. Einmal mehr also erweist sich die beanspruchte ,Naturalität ${ }^{6}$ und ,Metaphysikfreiheit' sanktionistischer Theorien als eine Chimäre, die nichts zu ihrer Rechtfertigung beiträgt, gleichgültig wie man diese Interessen selbst bewertet. Die antimetaphysische Rhetorik kann man deshalb beiseite lassen und sich auf den sachlichen Kern konzentrieren.

\section{Was ist eine Sanktion?}

,Sanktionen sind Maßnahmen, die für die von ihnen Betroffenen positive oder negative Effekte haben und von einer Kontrollinstanz absichtlich eingeführt werden, um die Konformität ihres Verhaltens mit bestimmten Standards prospektiv sicherzustellen oder zu fördern.$^{30}$ Diese Definition gilt auch

29 Vgl. Buchanan (1975) 94f., 130f.; Stemmer (2000) 104, und ders. (2002) 7. Beide Autoren verkennen den fiktionalen Charakter der Idee nicht, geben ihr aber bemerkenswert viel Kredit. Explikativ sanktionistische Ansprüche sind bei Buchanan allerdings nicht mit ihr verbunden, schon deshaib nicht, weil er (wie sein Beispiel automatisch zerstörten Diebesguts zeigt, a.a.O., 131) echte Sanktionen mit restitutiven und objektiv hindernden Maßnahmen in einen Topf wirft (vgl. unten S. 172f.). Stemmer dagegen meint $(2002,7)$, die Idee eines Sanktionierungsroboters weranschauliche nicht nur, wie „ein sanktionskonstituiertes Müssen (bzw. Nicht-Konnen) in die Welt" kommt, sondern sei eigentlich auch "das Beste" (2000, 104), was ein Sanktionist zur Konkretisierung seines Modells vorbringen kann. Angesichts der zugestandenen Fiktivität kommt das einem Offenbarungseid nahe. Doch zeigt die Bemerkung immerhin, daß Stemmer die extremen konzeptionellen Folgelasten, die eine sanktionistische ,Naturalisierung' des Sollens bzw. Müssens mit sich bringt, nicht völlig entgangen sind.

30 Reine Vergeltungsmaßnahmen (S. 165), denen jede Prospektivität fehlt, sind damit ausgeschlossen. Doch wenn es solche überhaupt gibt, ist ihre Ausgrenzung kein Verlust. Man muß nur Funktion und Legitimität von Sanktionen strikt auseinanderhalten. Auch rein retributive Straftheorien, die präventiven und reformativen Wirkungen keinerlei Bedeutung für die Recbtfertigung der Strafe beimessen, bestreiten ja in der Regel nicht, daß Strafgesetze auch die Funktion erfüllen, die Adressaten zu normenkonformem Handeln anzuhalten, und ihnen deshalb bekannt gemacht werden. Andernfalls müßten sie auch das Verkündungsgebot aufgeben, d.h. bereit sein zu strafen, obne daß die Betroffenen jemals erfahren wofür. 
für die Konditionierung von Tieren. Schon hier ist die Existenz einer intentional agierenden (menschlichen) Kontrollinstanz wesentlich, die Strafen und Belohnungen verhängt, um künftiges Verhalten zu beeinflussen, auch wenn Tiere, da sie nicht intentional überlegen können, noch keine ,Adressaten 'von Sollensansprüchen sind. ${ }^{31}$ Sanktionen bei Menschen dagegen sind adressiert, d.h. nicht nur intentional fundiert, sondern an Personen gerichtet, die den Anspruch bewußt erfassen und ihrerseits intentional erfüllen oder verletzen können. Auch wenn die Kontrollinstanz weitgehend anonym bleibt und den Eindruck erweckt, nur ein impersonales Etwas (ein ,Leviathan' oder ,soziales System') zu sein, können die Sollensansprüche und die Sanktionierung meist auf die Absichten von Personen zurückgeführt werden (simplifizierende systemtheoretische Makrobeschreibungen beiseite gesetzt). Zudem sind die kontrollierenden Individuen oder Gruppen (Wähler, Parlamentsmitglieder, Gremien) häufig auch kenntlich. Sanktionsgestützte Kontrolle kann natürlich auch eine Einzelperson ausüben, die dem Adressaten als Autorität gegenübertritt (z.B. als Elternteil, Chef, Diktator oder militärischer Vorgesetzter). $\mathrm{Ja}$, diese Person kann sogar mit dem Adressaten zusammenfallen, dann nämlich, wenn er sich selbst einem Standard unterworfen hat und einschlägig sanktioniert. ${ }^{32}$

31 Vorformen gibt es jedoch (vgl. Anm. 6). Deshalb ist es nicht reine Metaphorik, wenn man kolloqial davon spricht, daß der Dompteur seinen Raubkatzen mit der erhobenen Peitsche ,droht' und diese die Geste als ,Strafdrohung' auffassen, oder wenn man behauptet, ein gelehriges Dressurpferd, wisse', daß es nach erbrachter Leistung ein Zuckerstück ,zur Belohnung' erhält. Ist man bereit, höheren Tieren rudimentäre Formen von Planung und Absicht zuzuschreiben, lassen sich eventuell sogar jene, Drohgebärden', die man z.B. bei Schimpansen findet, ihrerseits schon als prospektiv kontrollierende Sanktionierungen deuten.

32 Manchmal wird das bestritten, törichterweise. Denn auch wenn dieses Verfahren zweifellos Willensstärke erfordert, die nicht bei allen Menschen im gleichen oder benötigten Maße vorhanden ist, so steht doch außer Frage, daß viele Menschen diese Bedingung erfüllen. Für selbstadressierte, nicht sanktionierte Sollensansprüche ist das ohnehin klar; jeder ernsthafte Vorsatz liefert ein Beispiel. Aber es gilt auch für einschlägig sanktionierte. Ein Raucher, der den Vorsatz gefaßt hat, nur noch 5 Zigaretten pro Tag zu rauchen, kann sich für jede durchgehaltene Woche mit einem Besuch in einem Gourmetrestaurant belohnen oder sich für jede überzählige Zigarette mit einer Spende von $10 €$ an die Krebshilfe selbst bestrafen, von vorsatzbedingten internen Sanktionen (wie Verlust des Selbstwertgefühls, Scham oder Ärger, S. 159) ganz zu schweigen. Ebenso kann ein Student seine nächste Urlaubsreise von einer bestandenen Prüfung abhängig machen, ein ehrgeiziger Sportler von einer bestimmten Plazierung im Wettkampf. Gewiß: wenn die Zeit reif ist, gibt es die Möglichkeit, das private Sanktionensystem samt dem Vorsatz wieder über den Haufen zu werfen. Dann eben würde man schwach, der ,innere Schweinehund' wäre stärker als das vernünftige ,bessere Ich'. Das kann der Fall sein, muß es aber und ist es oft genug nicht. Private Sanktionensysteme sind im Schnitt sicher weniger stabil als soziale, deshalb aber nicht inexistent oder prinzipiell nicht funktionsfähig. Zudem sind alle Systeme, die nicht auf der fiktiven Idee einer ,Sanktionsmaschinerie' (S. 169, Anm. 29) beruhen, sondern von intentionalem Handeln abhängen, prinzipiell nur so stabil, wie es die Willensstärke aller Beteiligten zuläßt. 
5.1 Der so bestimmte Sanktionsbegriff ist relativ weit. Er ist aber allemal eng genug, um vieles auszuschließen, was sich z.T. mit der Idee eines, sanktionskonstituierten Sollens ${ }^{\star}$ verbindet. Das gilt zunächst für positive oder negative Widerfahrnisse, die als, natürliche Folgen" menschlichen Handelns gelten. Kolloquial spricht man auch hier leichthin von Belohnungen oder Strafen ( "ohne Fleiß kein Preis“, ,wer zu spät kommt, den bestraft das Leben"). Darin kann sich die Vorstellung spiegeln, daß ein persönlicher Gott die scheinbar rein innerweltlichen, impersonalen Abläufe intentional kontrolliert. ${ }^{33}$ Dann ist die Rede von Sanktionen gerechtfertigt. Ohne diesen Hintergrund aber bleibt sie rein metaphorisch. Die negativen Folgen eines Griffs an die heiße Herdplatte oder dauerhaft ungesunden Lebens sind eben keine ,Strafen" im wörtlichen Sinne, obwohl auch sie lernabhängig voraussehbar sind und künftiges Handeln beeinflussen. Denn solche Folgen sind von der intentionalen Intervention einer Kontrollinstanz überhaupt unabhängig. Doch auch willensabhängig eintretende positive oder negative Folgen von Handlungen müssen keine Sanktionen sein, wenn die prospektive Kontrollabsicht fehlt. Dankbarkeit, Groll und Empörung, reaktive Sympathie oder Antipathie, soziale Anerkennung und Ausgrenzung sind zwar vom Willen mitbestimmt, haben als ,natürliche" sozialpsychologische Reaktionen aber ebenfalls noch keine sanktionierende Bedeutung. Umgekehrt schließt ihr, natürlicher oder sogar (genetisch, lern- oder sozialisationsbedingt) reflexartiger Eintritt echte Sanktionen dann nicht aus, wenn sie mit einschlägigen Kontrollabsichten entweder neu induziert oder als schon bestehende ausgenutzt werden. ${ }^{34}$

5.2 Aber selbst Maßnahmen, die absichtlich zur Verhaltenskontrolle eingeführt werden, haben nicht immer Sanktionscharakter. Ein relevanter Fall sind pädagogische und reformative Maßnabmen. Technische Regeln und Kunstregeln, Spielregeln, Verkehrsregeln, soziale Umgangsformen und moralische Normen im engeren Sinne werden von Kindern gewiß nicht allein

33 Zur Blätezeit der Physikoteleologie war dieser Gedanke auch philosophisch so respektabel, daß Butler (The Analogy of Religion, 1,2) daraus sogar einen Beweis für die Strafgerichtsbarkeit Gottes im Jenseits ableiten wollte. Im Volksglauben ist der Gedanke bis heute präsent. Die jüdisch-christliche Theologie weist ihn seit ,Hiob in ihrer Mehrheit zurück.

34 Letzteres gilt ja auch, wenn körperliche Lust- und Schmerzempfindungen durch externe Sankrionen ausgelöst werden (vgl. S. 158). Während der unverhoffte Kontakt mic Feuersenf zu einem nicht sanktionsbedingren Vermeidungsverhalten führen kann, ist dies zweifellos anders, wenn sich der entschlossene, aber nicht besonders willensstarke Raucher (Anm. 32) Feuersenf auf alle greifbaren Zigaretten schmiert, die seine normierte Fünfzahl übersteigen. Narürlich kommen auch nicht körperliche Empfindungen bzw. Gefühle der Lust und Unlust, die schon bestehen oder neu induziert werden, als Grundlage einer (selbst- oder fremdadressierten) intentionalen Kontrolle mit inrernen Sanktionen in Berracht. Stemmer (2000) 121. 151. 314, irrt deshalb, wenn er "affektiven Reaktionen“ wie Schuld- und Schamgefühlen pauschal den Status von Sanktionen abspricht. 
durch Strafen oder Belohnungen erlernt (S. 157), sondern auch und vor allem durch Vorbild und verbale Belehrung. Die meisten Regeln, denen sozialisierte Erwachsene (willentlich oder habituell) folgen, dürften auf diesem sanktionsfreien bzw. nur sporadisch sanktionengestützten Wege entstanden sein. Gleiches gilt für reformative sozialisatorische Maßnahmen. ${ }^{35}$ Zwar ist die Rede von, reformativen Strafzwecken' (S. 165) keineswegs unsinnig. Dann nämlich nicht, wenn die verhängten Maßnahmen (gemeinnützige Arbeiten, Schulungen, Therapien oder gar neurale Umprogrammierungen) erzwungen und den Adressaten vorgängig bekannt gemacht werden in der Absicht, ihr künftiges Handeln intentional zu beeinflussen. Dann aber handelt es sich eben nicht mehr um reine Besserungsmaßnahmen, sondern um Maßnahmen, die neben ihrer reformativen auch eine sanktionierende Funktion erfüllen. ${ }^{36}$

5.3 In anderen Fällen kann die Absicht vollständig fehlen, künftige Sollenskonformität durch Einfluß auf die Willensbildung zu fördern. Objektive Hindernisse z.B. sorgen dafür, daß gewisse Standards zwangsweise eingehalten werden, gleichgültig was die Betroffenen subjektiv wollen. Strafrechtlich geschützte Güter wie Eigentum oder Privatsphäre werden von jeher auch objektiv (durch Zäune, Türen und Schlösser) gesichert, ebenso andere öffentlich rechtliche Normen (durch Straßensperrungen, Sperrstunden, Ladenschlußzeiten) und nicht rechtsförmige, konventionell oder usuell etablierte Normierungen (durch Geländer, Zwanglauf, elektrische Sicherungen u.v.a.). Und die Erzwingung bestimmter Verhaltensstandards bei Tieren erfolgt natürlich auch nicht allein mit ,Zuckerbrot und Peitsche', sondern wird durch diverse Hinderungsmaßnahmen (Zwinger, Maulkörbe, Leinen) objektiv unterstützt. Trotz ihres $Z$ wangscharakters und ihrer prospektiven Kontrollfunktion sind solche Maßnahmen, die keinerlei, Drohpotential" enthalten und nicht an deviantes oder konformes Verhalten angehängt sind, keine Sanktionen. Für die Frage des Sanktionismus sind sie also irrelevant.

35 Wirksamer oft als der Anpfiff oder die Entlassungsdrohung des Chefs oder kollegiale soziale Achtung (Anm. 8) ist das persönliche ernste Gespräch, das Teamkollegen mit einem säumigen Mitglied führen. Ebenso weiß jeder gute Dirigent oder Forschungsleiter, daß mehr dazu gehört als Lob und Tadel, um sein Orchester bzw. seine betreuten WTissenschaftler zu Höchstleistungen nach dem Stande der Kunst zu bringen. Und einem Freund ins Gewissen zu reden, dessen Lebenswandel man mißbilligt, hat mit moralischer Sanktionierung gar nichts zu tun.

36 Wie bei der Retributivität (Anm. 30), so sind auch hier Funktion und Legitimität auseinanderzuhalten. Es bleibt möglich, Strafen allein von ihren Besserungswirkungen her zu rechtfertigen, obne Rücksicht auf präventive und retributive Aspekte. Die funktionale Eigenständigkeit des reformativen Aspekts wiederum zeigt sich daran, daß man, ginge es nur um Besserung, auch darauf verzichten könnte, die Betroffenen über die verhängten Maßnahmen und die Sollensansprüche aufzuklären. Natürlich dürfte das Ziel dann nur das faktisch (z.B. unbewu(3t habituierte oder neurologisch fixierte) normenkonforme Verbalten sein, nicht die Konformität aufgrund der (bewußten, intentionalen) Orientierung an einem bekannten und anerkannten Standard, 
5.4 Entsprechendes gilt für restitutive Maßnahmen, mit denen eingetretene Normenverletzungen von einer Kontrollinstanz rückgängig gemacht oder kompensiert werden. Wenn eine Mutter eingreift, um einem Kind das ihm von einem anderen Kind gewaltsam weggenommene Spielzeug zurückzugeben, kann diese Form der normierten Verhaltenskontrolle schwerlich als Sanktionierung gelten, ungeachtet des im Normalfall unbestreitbaren pädagogisch-sozialisatorischen Nutzens, den diese schlichte Restitutionsmaßnahme ebenfalls hat. Nicht anders steht es mit vergleichbaren Maßnahmen gegenüber Erwachsenen: Garantie- und Schadensersatzleistungen, Schmerzensgeldern, förmlichen Entschuldigungen und Widerrufen, Rückgabe unrechtmäßig enteigneter Besitzungen, Schuldenerstattung u.a. Auch ihre etwaige gerichtliche Erzwingbarkeit im Weigerungsfalle macht solche Maßnahmen noch nicht zu Sanktionen. Eine verfügte Restitutionszahlung etwa, die durch zwangsweise Kontoabbuchung oder Beschlagnahme durch den Gerichtsvollzieher umgesetzt wird, bleibt ihrem Sinn nach eine rein restitutive Maßnahme, die dem Eingreifen der Mutter vergleichbar ist. Erst die Drohung mit überkompensatorischem Zwangsgeld oder Beugehaft, um Unwillige zu willfähriger Herausgabe zu bewegen oder sie für ihre Unbotmäßigkeit zu bestrafen, ist eine echte Sanktion. Und natürlich ist es nicht ausgeschlossen, daß rechtsförmige oder andere Restitutionsmaßnahmen zugleich eine reformative oder präventiv sanktionierende Wirkung entfalten, die als solche mitbeabsichtigt sein kann. ${ }^{37}$

\section{Sanktionen als bloße Kaufpreise?}

Maßnahmen also, die Sollenskonformität allein durch objektive Behinderung oder auf pädagogischem, reformativem oder restitutivem Wege befördern, müssen in einer sanktionistischen Theorie ebenso aus dem Spiel bleiben wie relevante, natürliche' Folgen. Nur Sanktionen im prägnanten Sinn (S. 169) können die Theorie stützen. Und natürlich dürfen sie dies nicht nur in einer

37 Besonders deutlich ist das bei privaten, nicht rechtsförmigen Restitutionen, wie sie Eltern gegenüber ihren Kindern ausüben oder wie sie (als informelle, von allen Beteiligten mitgetragene Regulierungsmaßnahmen) in manchen Schulklassen oder Arbeitsteams praktiziert werden. Es gilt aber prinzipiell auch für rechtsfömige Restitutionen. Wie Kelsen (1946) 50, richtig gesehen hat, ist die sanktionierende Bedeutung restirutiver MaRnahmen immer sekundär und erst dann gegeben, wenn diese (gewolltermaßen) prospektw Einfluß auf die normenkonforme Willensbildung nehmen. Gleiches gilt für die (schuldunabhängige), strikte Haftung' im Strafrecht. Diese muß prima facie zwar als eine nichtsanktionierende, nicht prospekriv willensbildende und ziemlich barbarische Maßnahme erscheinen, wird durch geeignete Vorverlagerung des Adressierungszeitpunkts aber zu einer echten Sanktion; vgl. dazu Seebaß (1994) 410f. 
simplen, nichtintentionalen Variante tun, die schon auf Tiere zutrifft, sondern auch und vor allem in intentionalen, spezifisch menschlichen Formen. Auch hier aber gilt es, genauer hinzusehen, denn der Sinn von Sanktionen ist wandlungsfähig.

6.1 Nach gewöhnlicher, motivationaler Auffassung (S. 162f.) werden Sanktionen eingeführt, um den Willen der Adressaten zu sollenskonformem Handeln zu fördern. Formal tun sie dies durch Restriktionen der Handlungsfreiheit, Bei einem strafbewehrten Verbot bzw. Unterlassungsgebot der Form „ $G(-b)$ " bedeutet das etwa, daß anstelle der schlichten Handlungsoption „ $h$ " nur noch die komplexe Option " $b \wedge s$ " wählbar ist, wobei "s" eine Strafe darstellt, die bei der Willensbildung der Verbotsadressaten im allgemeinen negativ stärker zu Buche schlägt als ihr Wunsch nach $b$ positiv. ${ }^{38}$ Bei einem prämienunterstützten Gebot "G(b)" wiederum wird die schlichte, an sich indifferente oder negativ besetzte Option " $h$ " durch Hinzufügung einer (stärker) positiv besetzten Belohnung , $b$ " in die komplexe Handlungsoption , $b \wedge b$ "verwandelt, die von normalen Gebotsadressaten eher gewählt wird als,$\neg b$ “. Diese Grundstrukturen gelten im Prinzip für alle Arten von Normen und Sanktionen, interne genauso wie externe. Sie gelten aber, leicht modifiziert, nicht nur in normativen, sondern auch noch in anderen Kontexten.

Jedes Kauf- oder Tauschgeschäft, jede Nötigung oder Erpressung folgt prinzipiell demselben Muster. Stets nämlich wird eine Person, die etwas haben oder behalten, tun oder nicht tun will, von einer anderen so in ihrer Handlungsfreiheit und z.T. auch schon in ihrer Willensfreiheit ${ }^{39}$ beschnitten, daß ihr anstelle einer erwünschten einfachen nur eine komplexe Handlungsoption verbleibt, bei der sie etwas, das sie eigentlich nicht will, mit , in Kauf nehmen' muß. Natürlich gibt es bei der Reziprozität und Legitimität solcher fremdinduzierten Freiheitsbeschränkungen gravierende Unterschiede. Doch

38 Von den notorischen Komplikationen, die bei der Gewichtung von Wünschen und Willenshaltungen und ihrer Kommensurabilität untereinander auftreten, sehe ich zur Vereinfachung ab. Ausgespart bleiben auch die Probleme überindividueller Nomalitätsstandards und Risikogrenzen, die unvermeidlich sind, weil wir es - auch bei der Verknüpfung von $s$ und $b$ (vgl. Anm. 28 und 32) - meist nicht mit deterministischen Zusammenhängen zu tun haben, sondern mit probabilistischen; näheres dazu in Seebaß (1994) $388 \mathrm{ff}$.

39 Dayon kann immer dann die Rede sein, wenn durch den äußeren $Z$ wang Teile des Wünschens und Wollens der betroffenen Person ein abnormes Übergewicht über andere Teile bekommen, die für ihr wesensgemäßes Sein bzw. ihre wesensgemäße Selbstentfaltung ebenso bedeutsam wären; vgl. dazu Seebaß (1993 b) 224ff. Schon Aristoteles ist darauf aufmerksam geworden, daß äuBerer Zwang in gravierenden Fällen auch die Freiheir der Willensbildung tangiert, so daß das Ergebnis frei und unfrei zugleich erscheint (Nikomachische Ethik 1110a4-1110b9; Eudemische Ethik 1225a3-19). Die Augustinische Willenstheorie hat diesen Ansatz weitergeführt (vgl. Saarinen, 1994, ch. 2.1). Praktisch bedeutsam ist er im Strafrecht, z.B. in der Figur des "entschuldigenden Notstands" ( $\$ 35$ StGB). 
diese beruhen auf Zusatzkriterien, die die Handlungsstruktur nicht berühren. Scharfsichtige Theoretiker haben dies auch seit langem bemerkt, genauso wie die durchweg fließenden Grenzen, die zwischen den verschiedenen Fällen bestehen. ${ }^{40}$ Der reiche Viehbaron im wilden Westen, der die einzige Wasserstelle im Umkreis kontrolliert und die kleinen Viehhalter nach Herzenslust quälen kann, gilt als illegitimer Erpresser, den der gute Revolverheld mit Recht zur Strecke bringt. Anders dagegen verhält sich Hollywood (illegitimerweise) gegenüber dem prinzipiell strukturidentischen Wirken der United Fruit in Mittelamerika oder sonstigen ,global players', die ein faktisches Monopol besitzen. Die permanenten Kraftproben und Eiertänze der Kartellbehörden zeigen, wie vage die Grenzen hier immer noch sind. Aber auch unterhalb der nationalökonomischen oder globalen Ebene, bis hinab zum Feilschen auf dem Basar oder Tauschhändeln auf dem Schulhof, erweist sich der Schritt vom bloBen Geschäft zur Erpressung als ziemlich klein, mit oder ohne gesellschaftlich legitimierenden Hintergrund.

Wenn der einzige Wirt auf dem schönsten Aussichtsberg in der Gegend den erschöpften Wanderern saftige $10 €$ für ein Getränk abverlangt oder der Bäcker seinen Kunden 50 Cent (statt lediglich 20 oder gar nichts) für ein Baguettebrötchen, müssen diese tiefer in ihre Tasche greifen als sie es eigentlich gerne täten. Das kann gegebenenfalls ein Motiv für sie sein, künftig anders zu handeln (Verzicht auf den Berg oder Mitschleppen eines Getränkes usw.). Kaufpreise können also genauso prospektiv verhaltensmodifizierend wirken wie Strafen. Aber sind sie deshalb Sanktionen? Sicher nicht. Sie werden ja nicht mit der Absicht eingesetzt, das Handeln von Adressaten zu standardisieren. Ja eine Norm, die erfüllt werden soll, oder ein sonstiger (unkonditionalisierter ${ }^{41}$ ) Sollensanspruch liegen hier offenbar gar nicht vor. Letzteres kann der Fall sein, wenn normengeleitete Preispolitik betrieben wird. Benzin- und Tabaksteuer z.B. werden bei uns (neben anderen Zwecken) auch mit dem Ziel erhoben, die Luftverschmutzung oder die Krebsrate unter einem bestimmten Limit zu halten. Für die Politiker ist dies eine technische, für manche wohl auch eine paternalistisch-moralische Norm, an der sie ihr Handeln intentional ausrichten. Nicht so für die Bürger. Ihnen bleibt freigestellt, ob und in welchem Umfang sie weiterhin Auto fahren und rauchen wollen. Die Repression dieser Handlungen ist eben, anders als die von Mord und Diebstahl, nicht Gegenstand (sanktionierter oder nicht sanktionierter) sozialer Normen, die

40 So z.B. Abälard: Ethica, cap. 1-3; Kant (1990) 38-44; Sigwart (1889) $198 f$.

41 Bedingte Ansprüche gibt es natürlich. Wenn ein bestimmter Wanderer ein Getränk haben will, fordert der Bergwirt seine $10 €$ von ihm. Aber er verlangt nicht und kann nicht verlangen, daß alle (faktischen oder potentiellen) Bergwanderer ein 10-€-Getränke-Verhalten zeigen, auch wenn er sich dies vielleicht wünscht. 
alle erfüllen und bei ihrer Willensbildung beachten sollen. Und deshalb sind Steuern genausowenig wie bloße Kaufpreise Sanktionen. ${ }^{42}$

6.2 Das hat Konsequenzen für die Beurteilung des Sanktionismus. Denn er will ja nicht nur die Motivation zu sollenskonformem Wollen und Handeln, sondern das Sollen selbst auf die Verknüpfung von Handlungen mit positiven oder negativen Folgen zurückführen. Für ihn also ist z.B. das Bestehen

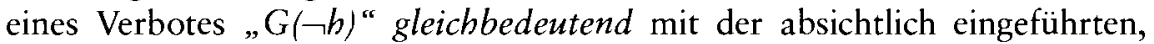
objektiven Beschränkung der zuvor offenen Handlungsfreiheit gegenüber „h" auf die Option ", $h \wedge s$ “. Der deontische Modaloperator "G" erweist sich damit als überflüssig. Es gibt eigentlich keine Gebote oder Verbote mehr, deren Befolgung durch Strafbewehrung zu fördern wäre, sondern nur noch faktische Freiheitsbeschränkungen (unter Absehung von den Problemen aus Abschnitt 4.2). Damit wird aber auch die Differenz zwischen Sanktionen im prägnanten Sinn und bloßen Steuern und Kaufpreisen hinfällig. Strafen sind nun nichts anderes mehr als Preise, die man für ein bestimmtes Verhalten zahlen muß. Konsequente Sanktionisten erkennen das und die damit verbundene Änderung im Begriff der "Sanktion" auch an. ${ }^{43}$ Weniger klar ist, wie weit sie bereit sind, konzeptionelle Konsequenzen daraus zu ziehen.

Ein Indiz für bestehende Vorbehalte ist der Gedanke, ${ }^{44}$ nur negative Sanktionen könnten stärkere Formen des Sollens begründen, positive dagegen allenfalls schwächere. Doch wenn, Sanktionen' nicht mehr sind als Kaufpreise, darf diese Differenz keine Bedeutung haben. Es ist dann nur eine nachgeordnete empirisch-psychologische Frage, auf welchem Wege, d.h. durch welche Veränderungen der Freiheitsräume, der gewünschte Effekt eher erreicht wird. Anstatt die Autobesitzer zu besteuern, könnte man, wenn dies wirksamer ist, auch den Verzicht aufs Auto mit großzügigen Steuerbefreiungen fördern. Und es ist nicht einzusehen, warum das bei strafrechtlichen oder moralischen

42 So auch z.B. Hart (1968) 6f., verbunden mit einer einschlägigen Kritik an Kelsen (Anm. 27). Steuern die zur Verhaltenssteuerung eingesetzt werden, sind Hinderungsmaßnabmen, die bestimmte Handlungen objektiv schwieriger machen (Abschnitt 5.3). Formal sind sie also eher dem Maulkorb oder dem Zwinger als der erhobenen Peitsche zu vergleichen, mit denen man Hunde von einem unerwünschten Verhalten abhält.

Im übrigen schließt ihr Einsatz zur Verhaltenskontrolle nicht aus, daß unsere Benzin- und Tabaksteuer auch und viele andere Steuern sogar ausschließlich zur Finanzierung des Staates eingesetzt werden, gestützt auf die Erwartung, daß alle oder die meisten Bürger gewisse steuerpflichtige Aktivitäten nicht aufgeben werden bzw. können. Ebensowenig aber ist ausgeschlossen, daß genuine Strafen (wie bereits Hobbes bemerkte, vgl. Anm. 48) partiell oder vollständig zu Geldbeschaffungsmaßnahmen umfunktioniert werden, wie heute z.B. manche ,Radarfallen'.

43 So etwas verschleiernd und zögernd Tugendhat (1997) 128. 139, weniger verblümt Stemmer (2000) $137 \mathrm{ff}$.

44 Vgl. Stemmer (2000) 156f., ähnlich schon Bentham, vgl. Hacker (1973) 137, 142; Austin (1832, ${ }^{5} 1885$ ) 23f.; v. Wright (1963b) 193, sowie ders. (1980) $48 \mathrm{f}$. 
Normen prinzipiell anders sein sollte. Der gegenteilige Eindruck kann nur entstehen, wenn stillschweigend unterstellt wird, daß es hier um Ansprüche geht, die absolut gelten und daher nicht abhängig sein können von kontingenten psychologischen Tatsachen über die Wirkung von Prämien und Preisen. ${ }^{45}$ Konsequent sanktionistisch ist eine solche Auffassung sicherlich nicht.

6.3 Aber auch mit der Beschränkung auf negative Sanktionen hat deren Assimilation an bloße Kaufpreise zwei extrem befremdliche Konsequenzen. Die erste betrifft die Haltung der Adressaten. Diese wissen, daß bestimmte Handlungen kostspielig werden können und daß die normgebende Autorität, also z.B. die staatliche Legislative in Verbindung mit den Strafverfolgungsbehörden, dies beabsichtigt. Mehr aber wird ihnen nicht gesagt. Konkret heißt das etwa, daß $\$ 211$ StGB folgende Botschaft vermittelt. An sich, so wird jedem Bürger gesagt, habe der deutsche Staat, d.h. die im Parlament repräsentierte Gemeinschaft aller wahlmündigen Deutschen, gar nichts dagegen, wenn jemand einen anderen (auf die im Tatbestandsteil des Gesetzes beschriebene Weise, vgl. S. 165f.) ermordet, genausowenig wie er etwas dagegen hat, daß jemand Auto fährt oder ein Brötchen kauft. Nur müsse der Betreffende eben, genauso wie er Benzin- und Kraftfahrzeugsteuer entrichten oder 50 Cent an den Bäcker zahlen muß, auch die für diese Handlung vorgesehene Gegenleistung erbringen, d.h. entweder lebenslang ins Gefängnis gehen oder es schaffen, den Verfolgungsbehörden lebenslang zu entkommen. Gewiß, beide Leistungsformen, der Freiheitsentzug genauso wie die Aufwendungen zur Organisation einer perfekten Flucht oder Tatverdeckung, sind ein relativ hoher Preis, verglichen mit den 50 Cent für den Bäcker oder der Steuerzahlung an Vater Staat. Aber es war nun einmal (nach einem alten Werbetext) "schon immer etwas teurer, einen besonderen Geschmack zu haben ". Schließlich muß jemand, der es sich in den Kopf gesetzt hat, mit der NASA zum Mond zu fliegen oder sein Hirn nach dem Ableben tiefgefrieren und irgendwann reanimieren zu lassen,

45 Zweifellos hat der Asymmetriegedanke auch einen verdeckten motivationalen Hintergrund, nämlich die alte Annahme, daß Menschen, wenn nicht allein, so doch wesentlich stärker durch Unlast motiviert werden als durch Lust, klassisch artikuliert z.B. von Locke (Essay, II, 21, 31ff.), literarisch ironisiert von Withelm Busch (Gedicht „Ich saß vergnüglich bei dem Wein", in: Kritik des Herzens, 1875). Doch wie immer es mit dieser kritikwürdigen und oft kritisierten Hyporhese stehen mag, sie könnte bestenfalls verständlich machen, warum die psychologische Kontingenz bei Belohnungen eher ins Auge springt als bei Strafen. Konzeptionell wäre sie ohne Belang. Zudem entsteht der Verdacht einer versteckten Inkonsequenz auf der explikativen Ebene. Denn zugrundeliegt offenbar auch der Gedanke, daß negative Sanktionen, zumindest im strafrechtlichen und moralischen Bereich, mit sozialer Achtung und korrespondierenden Gefüblen von Scham und Schuld verbunden sind (\$. 159f.), bei denen man normalerweise eben voraussetzt, daß sie durch Normen fundiert sind, die unabhängig von Sanktionen Geltung haben (vgl. S. 165, Anm. 24). 
ebenfalls einiges investieren, einschließlich aufwendiger Vorbereitungen und eines nicht unerheblichen Lebensrisikos.

Nun, für den gemeinen Menschenverstand ist klar, daß hier etwas prinzipiell schiefläuft. Und natürlich kann man nicht sagen, diese sarkastische Beschreibung treffe zwar die rein rechtliche Seite der Sache, Mord aber sei auch moralisch geächtet und verboten. Denn für den radikalen Sanktionisten folgt die Moral demselben Schema. Mehr noch. Wenn negative Sanktionen nichts anderes sind als Preise, die Spielräume der Handlungsfreiheit verengen und dadurch Verhaltenskontrolle ausüben, geraten neben den Adressaten, zweitens, auch die Normgeber und die mit der Umsetzung Beauftragten in eine schiefe Position. Die deviant Agierenden bewegen sich ja per definitionem immer im Rahmen des Vorgesehenen. Ihnen kann man daher keinen Vorwurf machen, wenn die sozial erwünschten Konformitätsstandards nicht erreicht werden, die öffentliche, Zahlungsmoral' also zu wünschen übrig läßt. Vielmehr müßte man, statt der geschäftlich, vorleistenden“ Mörder, die säumigen Polizeibeamten und Staatsanwälte in Regreß nehmen, wenn sie die ,fällige Gegenleistung' nicht erbringen und zu viele Täter davonkommen lassen. Oder noch besser vielleicht, da früher ansetzend, das Parlament und seine Wähler wären als eigentliche Urheber der vielen Morde dingfest zu machen, weil sie kein Preissystem für Mord entwickelt haben, das die erwünschte Marge liefert. ${ }^{46}$

6.4 Die Gleichstellung von Sanktionen mit bloßen Kaufpreisen, zu der die sanktionistische Theorie des Sollens führt, ist also extrem kontraintuitiv. Sie nivelliert (1) die Differenz zwischen normativen und anders begründeten Arten absichtlicher Freiheitsbeschränkung und beinhaltet (2), wenn nicht die völlige Destruktion, so doch eine fundamentale Revision des traditionellen Systems der normativen Verhaltenskontrolle, das mit verantwortlich agierenden Normadressaten rechnet. ${ }^{47}$ Dies allein kann hinreichen, um die Idee

46 Daß die Verantwortung für eine motivational unzureichende Strafe und thre Folgen letztlich auf den Gesetzgeber zurückfällt, wenn die Strafdrohung als einzig ausschlaggebendes Handlungsmotiv gilt, ist schon von Hobbes (De cive, cap. 13, $\$ 16$ ) sehr klar gesehen worden. Verbunden mit einer Grundsatzkritik an deterministischen Motivationstheorien findet er sich z.B. bei Th. Reid (1969) 293. Positivisten dagegen (wie Schlick, 1984, 112f.) übergehen den Punkt geflissentlich und folgen damit (unbewußt) einer langen theologischen Tradition, die so das Theodizeeproblem zu entschärfen hoffe. Dabei wird seine Bedeutung beim Obergang vom motivationalen zum explikativen Sanktionismus noch erheblich verstärkt. Denn mit der Sanktionierung soll hier ja die Unterscheidung zwischen Recht und Unrecht überhaupt stehen und fallen. Die bloße Absichtserklärung des Gesetzgebers, mit der Strafdrohung deviantes Verhalten verhindern oder unter einer bestimmten Marge halten zu wollen, kann ihn schwerlich entlasten. Und wenn er das ,Eintreiben' der von ibm gesetzten Kaufpreise an die Verfolgungsbehörden delegiert, so ergibt auch das allenfalls eine partielle Entlastung angesichts der in Anm. 28 skizzierren Probleme.

47 Naheres dazu bei SeebaR (1994) 381-388; (1993 a) Kap. I u. VI. 
(die ja auch manche Sympathisanten zögern läßt, Anm. 27 und 43) definitiv zu verabschieden, was die meisten Theoretiker auch tun. ${ }^{48}$ Ein wahrer Sanktionist ist durch mangelnde Gefolgschaft allerdings kaum zu beeindrucken. Er versteht sich als Speerspitze normentheoretischer Aufklärung und rechnet darauf, daß Traditionalismus, Gedankenlosigkeit und Obskurantismus zwar anfänglich Widerstand leisten, letztlich aber der Wahrheit weichen müssen. Diese heroische Wendung weckt Verdacht. Schließlich haben sich proklamierte Fortschritte oft genug nur als des Kaisers neue Kleider erwiesen. Ja, nach dem Wegfall des Argumentes der ,Metaphysikfreiheit" (Abschnitt 4) spricht für den Sanktionismus eigentlich nichts. Eher könnte man sagen, $\mathrm{daß}$ schon seine Selbstetikettierung kaiserlich-illusionistische Züge trägt, da es eben nicht um Sanktionen geht, sondern um Kaufpreise oder sogar nur um reformative, restitutive oder objektiv hindernde Maßnahmen (Abschnitt 5). Geben wir dem Sanktionisten aber noch eine Chance! Lassen wir uns auf seinen Aufklärungsgestus ein und stellen wir uns seiner legitimen Gegenfrage, woher denn um alles in der Welt das Sollen kommen soll, wenn nicht aus angehängten positiven oder negativen Folgen.

\section{Kategorisches und hypothetisches Sollen}

Zunächst allerdings muß der Begriff des Sollens präzisiert und differenziert werden, denn es gibt verschiedene Formen, von denen vielleicht nicht alle einschlägig sind. Eine Bitte, Empfehlang oder ein bloßer Rat erwecken, obwohl auch sie ein Sollen enthalten, kaum den Eindruck, notwendig mit etwas verbunden zu sein, das sich auch nur entfernt als, Sanktion' bezeichnen ließe. Deshalb werden schwächere Formen wie diese im allgemeinen auch ausgenommen. Das ist ein Zugeständnis, das prima facie klein erscheint, im Kontext eines explikativen Sanktionismus jedoch die gravierende Konsequenz hat, daß es keinen Gattungsbegriff mehr gibt, unter den alle Arten des Sollens fallen (S. 165). Wenn diese Spaltung plausibel werden soll, muß vor allem aufgezeigt werden, was die stärkeren, angeblich nur sanktionistisch zu analy ierenden

$48 \mathrm{Vgl}$. für die Rechtswissenschaft z.B. Baumann / Weber (91985) 26, und Hart (1968) 6-8, 44. Beispiele aus der Philosophie liefern neben vielen anderen Bentham (1970) 302f. (trotz seiner sanktionistischen Tendenzen an anderen Stellen, vgl. Anm. 11) und besonders instruktiv Hobbes: De cive, cap. 14, $\$ 23$; Leviathan, XXVIII (9. u. 18. Absatz). Hobbes hat sehr klar gesehen, daß Kaufpreise keine wirklichen Strafen sind und dem Sinn eines unbedingten Gebots widersprechen. Die Kaufpreis-Deutung der Strafgesetze ist für ihn deshalb entweder ein Zeichen dafür, daß sie nicht unbedingt gelten, sondern nur als bedingte erlassen wurden, oder daß der Gesetzgeber sie überhaupt nur als Mittel zur staatichen Geldbeschaffung versteht (vgl. Anm, 42). 
Sollensbegriffe auszeichnet. Von unverbindlichen Empfehlungen, Ratschlägen oder Bitten scheinen sie dadurch geschieden zu sein, daß sie verbindliche Forderungen und Verpflichtungen enthalten. Das Sollen hat hier den Charakter des unabdingbaren, kategorischen Mïssens, das nicht mehr unter Vorbehalt steht, d.h. nicht konditionalisiert oder relativiert ist. Begrifflich verweist dies zurück auf Kant, dessen Unterscheidung zwischen ,kategorischen' und ,hypothetischen Imperativen' denn auch die Folie bildet, z.T. verbunden mit der Behauptung, daß nach dem Scheitern von Kants Konzept nur der Sanktionismus als Theorie eines kategorischen Müssens übrig bleibe. ${ }^{49}$ Hier lohnt es, etwas genauer hinzusehen. Denn Kants Begriff des ,kategorischen Imperativs ${ }^{6}$ ist ein sehr spezieller und anspruchsvoller, der verschiedene Merkmale in sich vereint, die keineswegs für alle Arten des kategorischen Müssens gelten.

7.1 Begrifflich zentral ist nur der Gegensatz von bedingten und unbedingten Forderungen. Kant hat gesehen, daß Sätze der Form „Tue b!“ oder „Du $m u \beta t$ b tun " (= kategorische Imperative) semantisch und logisch signifikant verschieden sind von Sätzen der Form „Wenn p, tue b!“ oder „Wenn p, $m u \beta t d u$ b tun " (= hypothetische Imperative). ${ }^{50}$ Aber er hat sich die generelle semantische Analyse gespart, weil ihn von vornherein nur speziellere Arten interessierten. So hat er bei den hypothetischen Imperativen nur Versionen ins Auge gefaßt, bei denen an der Stelle von „p "Sätze wie „Du willst, daß q“ (o.ä.) auftreten. Deshalb ist das bedingte Müssen, artikuliert in "technischen" oder „pragmatischen Imperativen“, bei Kant immer ein prudentielles, also volitiv relativiertes. Das ist jedoch nicht der einzige Sinn, den konditionalisierte Muß-Sätze haben können, und es ist ratsam, wenigstens zwei relevante andere explizit zu machen.

Der erste läßt sich am Beispiel eines Kindes erläutern, dem man vor dem ersten Schulweg die Regel einschärft: „Wenn die Ampel Rot zeigt, mußt du stehen bleiben ". So klug es auch ist, ihr zu folgen, so artikuliert sie doch selbst kein prudentielles, hypothetisches Müssen, sondern ein kategorisch gefaßtes Verbot bzw. Gebot (S. 174) der Straßenverkehrsordnung. Wenn „r" für das Rotsein der Ampel steht und „s" für das Stehenbleiben, folgt sie dem Schema , $G \neg(r \wedge \neg s)$ ". Sie enthält also, entgegen dem ersten Anschein, keine bedingte Forderung, sondern eine unbedingte. Diese allerdings hat einen komplexen, konjunktiven Gehalt, der sich (nach de Morgan) konditional reformulieren läßt und umgangssprachlich gewöhnlich in dieser Form auftritt. Sie folgt auch

49 Tugendhat (1993) 43ff., 70 u.ö.; (2001) 8, ähnlich auch Stemmer (2000) 64ff., $207 \mathrm{f}$.

50 Trotz einiger terminologischer, z.T. auch sachlicher Varianzen ist Kants Abgrenzung seit ca. $1775 \mathrm{im}$ wesentlichen gleich geblieben, zumindest in den Hinsichten, die hier von Interesse sind. Deshalb wird sie im folgenden summarisch behandelt. Die wichtigsten Textstellen sind, chronologisch geordnet: Kant (1990) 25f. 44; Akademie-Ausgabe, Bd. XXVIII/1, 256f.; Bd. IV, 412-420; Bd. V, 19-21, 25f.; Bd. XX, 195-201; Bd. V, 172f.; Bd. VI, 221-223. 
nicht etwa, wie es bei oberflächlicher Analyse scheinen mag, dem Schema: „Wenn r, dann $G(s)$ ", das dem zweiten erwähnten Sinn eines nicht prudentiellen konditionalen Müssens entspricht. Denn hier geht es nicht einmal mehr um eine kategorische Forderung mit komplexem, konditionalisierbaren Gehalt, sondern nur noch um eine kategorische Forderung mit einfachem (oder auch per Einsetzung an der Stelle von "s" beliebig komplexem) Inhalt,

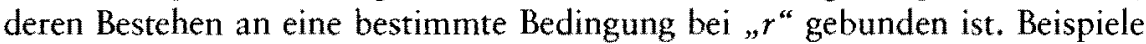
dafür wären staatliche Notverordnungen oder vorformulierte militärische Befehle, die erst durch bestimmte Personen in Kraft gesetzt werden. Während sich im ersten Fall ein scheinbar hypothetisches Müssen durch Analyse als kategorisches erweist, steht im zweiten Fall ein unverkennbar kategorisches Müssen unter dem Vorbehalt, daß die im Wenn-Teil des Satzes artikulierte Hypothese erfüllt ist.

Diese letztere Struktur spielt nun aber auch beim prudentiell-hypothetischen Müssen eine bedeutende Rolle. Ein Arzt z.B. sagt einem Patienten: „Sie müssen mit dem Rauchen aufhören". Das ist eine kategorische Forderung. Allerdings enthält sie kein originäres, unhinterfragbares oder der ärztlichen Willkür entsprungenes Müssen, sondern ein abgeleitetes und insofern bedingtes. Es ergibt sich als Konklusion eines, praktischen Syllogismus, dessen Obersatz durch den (vom Arzt unterstellten) Gesundheitswillen des Patienten gebildet wird und dessen Untersatz in der ärztlichen Diagnose besteht, daß seine Gesundheit Rauchverzicht voraussetzt. Das ist die komplette Analyse. Schenkt man sich nun aber die separate Formulierung des Untersatzes und macht den Obersatz in einer vorangestellten Wenn-Klausel explizit, ergibt sich ein prudentieller ,hypothetischer Imperativ“ im Sinne Kants: „Wenn Sie gesund werden wollen, müssen Sie mit dem Rauchen aufhören ". ${ }^{51}$ Dieser Imperativ erweist sich somit als Sonderfall eines bedingten kategorischen Müssens. Ob es in Kraft ist, hängt an der Erfülltheit seiner Bedingung, die hier aus der Konjunktion zweier Prämissen besteht. Ist eine von beiden nicht erfüllt oder (z.B. in einer Phase des unentschiedenen, ergebnisoffenen Überlegens) zweifelhaft, steht die resultierende Forderung unter Vorbehalt, genau wie ein vorformulierter, noch nicht in Kraft gesetzter Befehl, nur eben mit

$\$ 1$ Die umgangssprachliche semantische Sparsamkeit solcher prudentiell-hypothetischen Sätze besteht u.a. darin, daß "müssen " gleichzeitig in (mindestens) dreifacher Bedeutung verwendet wird: (1) als kausales bzw, naturgesetzliches Müssen im Untersatz des zugrundeliegenden praktischen Syllogismus, (2) als logisches Müssen der beanspruchten syllogistischen Schlußfolgerung und (3) als deontisches Müssen in der sich ergebenden, kategorisch imperativischen Konklusion. Die mangelnde Differenziertheit Kants (wie vieler anderer Autoren) an dieser Stelle ist einer der Gründe, die seine Unterscheidung zwischen ,kategorischen' und ,hypothetischen Imperativen' mißverständlich machen und zur Verwirrung in der Literatur beitragen, wie z.B. auch bei Stemmer (2000) 53-63. Von den notorischen Schwierigkeiten, die mit der Annahme verbunden sind, der Folgerungscharakter, praktischer Syllogismen' sei logisch zwingend, sehe ich hier zur Vereinfachung ab. 
einer komplexen (teils volitiven, teils assertorischen) Bedingung. Sind beide Prämissen aber erfüllt, impliziert der hypothetische zugleich einen kategorischen Muß-Satz. ${ }^{52}$

An dieser abgeleiteten Kategorizität ist nichts Geheimnisvolles. Sie ist vielmehr, wie das Arztbeispiel und zahllose andere Beispiele zeigen, menschliche Normalität. Man muß nur strikt darauf achten, das Bestehen bzw. Erheben einer Forderung nicht mit den Gründen für sie zu vermischen. ${ }^{53}$ Erst der Begründungshintergrund eines vorliegenden kategorischen Müssens kann Auskunft darüber geben, ob es abgeleitet ist oder originär. Er entscheidet also auch darüber, ob und in welcher Weise es konditionalisiert ist. Der Sinn dieses Müssens, d.h. sein eigener vorbehaltloser Anspruch, bleibt davon unberührt. Sollte er deshalb, im Gegensatz zu schwächeren Sollensansprüchen oder Ansprüchen unter Vorbehalt, tatsächlich sanktionistisch zu explizieren sein, müßte sich dies bei allen Muß-Sätzen dieses Typs zeigen, auch bei solchen mit einem prudentiellen Hintergrund. Da diese sich aber auch und zuallererst aus praktisch-syllogistischen Schlüssen ergeben, bei denen der Untersatz, natürliche' bzw. naturgesetzliche (z.B. medizinische) Zusammenhänge betrifft, sich also nicht sanktionistisch interpretieren lassen, ${ }^{54}$ ergibt sich daraus ein weiterer prinzipieller Einwand gegen den Sanktionismus, der selbst dann zum Tragen käme, wenn man die kontraintuitive Assimilation an Kaufpreise mitmachte.

52 Das gilt, wie bei allen praktischen Schlüssen, natürlich nur (wenn überhaupt, Anm. 51) unter der Voraussetzung, daß keine weiteren Prämissen im Spiel sind, die die logische Folgerung konterkarieren könnten. Diese Bedingung ist jedoch in praxi selten erfüllt. Der praktisch-syllogistische Schluß betrifft also in der Regel nur einen Teilschritt innerhalb eines Überlegungsprozesses, der in Wirklichkeit viel komplexer und ausgedehnter ist. Hier kann dem nicht weiter nachgegangen werden; zu einigen wichtigen Aspekten vgl. Seebaß (1993 a) Kap. IV, 6.

53 Forderungen unterscheiden sich darin nicht von Behauptungen. Zu wissen, daß jemand einen Wahrheitsanspruch erhebt, heißt nicht schon zu wissen, ob oder welche Gründe hinter ihm stehen und ob er überhaupt zu begründen ist. Auch ein gedruckter assertorischer Satz, dessen Begründung uns ebenso verborgen bleibt wie sein Autor, wie z.B. ein Satz im Brockhaus oder ein Satz in der Zeitung, bleibt semantisch ein Aussagesatz, der einen Anspruch auf Wahrheit erhebt, gleichgültig ob wir ihn für wahr und begründet halten oder bezweifeln. Überdies kann ein und derselbe wahre Satz oft auf verschiedene Weise begründet bzw. als wahr erwiesen werden. Die Begründungsfrage muß also prinzipiell vom erhobenen Anspruch getrennt werden, bei optativischen und imperativischen Sätzen genauso wie bei assertorischen.

$54 \mathrm{Vgl}$. oben S. 171. Gelegentlich wird behauptet, schon das Verfehlen eines gewollten Zwecks aufgrund eines nicht ergriffenen, notwendigen Mittels habe Sanktionscharakter, so z.B. Tugendhat (1993) 43, 45. Wäre dies so, wären ,Sanktionen" wohlfeil. Jeder unerfüllte Wunsch oder Wille, jede falsifizierte Behauptung (Anm. 53) enthielte dann eine Art von ,Bestrafung. Das ist absurd. Erklärbar wird der Gedanke einerseits durch die undifferenzierte Einbeziehung, natürlicher Folgen', andererseits durch die unten (S. 196) diagnostizierte anhaltende Fixierung auf die Idee, intentionale Zustände wie die des Meinens und Wollens müßten sich kausaldispositionell interpretieren lassen. 
7.2 Bedingte und unbedingte Forderungen (Muß-Sätze, Imperative) können auch partikulär sein. Was ein einzelner Befehlsempfänger einmal tun muß oder ein bestimmter Patient dauerhaft, muß ja nichts sein, was für andere Personen und Zeiten ebenfalls gilt. Kant haben diese Fälle nicht interessiert. Seine hypothetischen und kategorischen Imperative sind von vornherein generelle "praktische Prinzipien“ („Gesetze“ o.ä.). Ja, er behauptet sogar, daß es nur einen einzigen, wenn auch verschieden formulierbaren Imperativ gibt, der das Prädikat "kategorisch" verdient, und daß dieser zugleich moralisch spezifiziert ist. ${ }^{55}$ Darin liegen weitere, gravierende Begriffsverengungen. Auch wenn man die letztgenannten, besonders problematischen ausklammert und die Beschränkung auf generelle Sätze mitmacht, bleibt Kants Konzept präzisierungsbedürftig. Denn welche Generalität ist gemeint? Hier gilt es, weiter zu differenzieren.

Generell können Forderungen zunächst im Hinblick auf ihren Inbalt sein, dann nämlich, wenn sie sich nicht auf einzelne Handlungen beziehen, sondern auf Handlungstypen. Kategorisch verboten z.B. ist nicht nur das Töten eines bestimmten Menschen, sondern das Töten von Menschen überhaupt. Hypothetisch geboten ist der Tritt aufs Bremspedal nicht nur beim gegenwärtigen Versuch, vor einer roten Ampel anzuhalten, sondern immer, wenn man sein Auto stoppen will. Beides gilt für beliebige Menschen. Inhaltlich generell kann jedoch auch eine private Lebensregel sein („No sports, whiskey, and cigars!") oder ein Rezept, das der Arzt einem einzelnen Patienten verordnet $($ "Nie mehr rauchen!“, „Jeden Morgen 1 Dragee nach dem Frühstück! “). Inhaltlich generelle Forderungen also sind prinzipiell indifferent gegenüber der Frage, an welche und wieviele Personen sie adressiert sind.

Ihre Generalität ist deshalb strikt von derjenigen zu unterscheiden, die die Adressaten betrifft. Aber auch hier sind weitere Differenzierungen nötig. Allsätze der Form,$\forall x)[G(H x)]$ “ oder der verkürzten, implizit praktisch-syllogistischen Form ,,$\forall x)$ [Wenn $x$ will, daß p, dann $G(H x)$ ] “ erlauben verschiedene, mehr oder weniger anspruchsvolle Deutungen. Das Universum der Individuen, über die quantifiziert wird, ist nicht gleichgroß. Kunst- oder Spielregeln gelten nur für Personen, die diese Künste und Spiele betreiben, Standesregeln, Vereinsstatuten oder interne Regularien von Firmen oder Behörden nur für die Mitglieder. Staatliche Gesetze, einschließlich solcher mit Verfassungsrang,

55 Kants beanspruchter, verdächtig knapper Evidenzbeweis für diese Behauptung („weiß ich sofort", Akademie-Ausgabe, Bd. IV, 420) wird etwas verständlicher vor dem Hintergrund des extremen Generalitätsanspruchs bei den Adressaten, den er erhebt (vgl. S. 184). Auch damit läßt er sich jedoch nicht rechtfertigen, sondern allenfalls in Kombination mit Kants ebenso starken und hochproblematischen Annahmen über die ,Formalität' und ,Materiefreiheit beim Inhalt praktischer Prinzipien, denen man kategorische Geltung zuschreiben kann. Ich sehe davon im folgenden ab, ebenso von den Problemen, die mit der behaupteten Aquivalenz der verschiedenen Formulierungen des ,kategorischen Imperativs' verbunden sind. 
sind zwar an alle Bürger oder Besucher des Landes adressiert, nicht aber an alle Menschen. Letzteres trifft erst auf universale Menschenrechte und -pflichten zu bzw. auf sie stützende universale Moralprinzipien. Auch diese müssen sich aber nicht notwendig auf alle menschlichen Individuen erstrecken, die potentielle Adressaten sind, einschließlich z.B. künftiger Generationen. Sie könnten es freilich. Kant ist in einer Hinsicht sogar noch weiter gegangen, indem er seinen einen und einzigen ,kategorischen Imperativ' nicht nur für alle Menschen, sondern für alle Vernunftwesen überhaupt gelten ließ, auch für etwaige über- und außermenschliche. Der Allgemeingültigkeitsanspruch genereller Forderungen, bedingter wie unbedingter, kann also sehr verschieden sein und muß jeweils sorgfältig spezifiziert werden.

\subsection{Die vorstehenden Differenzierungen und Präzisierungen des tradierten} Kantischen Begriffspaars sind alles andere als erschöpfend, genügen aber, um ein schärferes Licht auf die These (S. 179f.) zu werfen, daß es speziell das Sollen in der Form des unbedingten, kategorischen Müssens ist, das einer sanktionistischen Explikation bedarf. Auch diese Form umfaßt ja verschiedenste Arten von Forderungen: partikuläre wie generelle, originäre wie abgeleitete und insofern bedingte. Kants ,kategorischer Imperativ' ist ein Sonderfall, und zwar ein extrem anspruchsvoller. Ihn zu verwerfen, bedeutet also nicht viel, bleiben doch konzeptionell zabllose Alternativen offen. Was also sollte der Sanktionist aus einer Ablehnung Kants gewinnen können? Mehr noch. Kants Konzept, so extrem es auch ist, bleibt eine Möglichkeit, kategorisches Müssen zu spezifizieren. Es müßte sich deshalb, träfe der Sanktionismus zu, selbst durch ihn explizieren lassen. Von einer unausweichlichen Alternative von Kantianischem und sanktionistischem Müssen (S. 180 Anm. 49) kann also gar keine Rede sein, und nach dem Vorstehenden ist leicht zu sehen, wo hier die Fehler liegen.

Zunächst fehlt es an der notwendigen Differenzierung zwischen begrifflicher Explikation und Begründung (S. 182). Kants ,kategorischer Imperativ fordert von allen, sich in ihrem Handeln dem Prinzip der universalen moralischen Gleichbehandlung aller zu unterwerfen. Als solcher ist er natürlich begründungsbedürftig. Kant verweist seine Leser dabei an das „Faktum“ der "reinen praktischen Vernunft". Doch eine solche können nicht allzuviele in sich entdecken. Deswegen halten sie entweder die Forderung selbst für unbegründbar oder suchen nach einer alternativen Begründung: wenn nicht für Kants ,kategorischen Imperativ', so doch vielleicht für etwas, das ihm an Gehalt und Reichweite des Adressatenkreises nahekommt. Wenn theonome oder naturrechtliche Begründungen aber ebenfalls ausscheiden (S. 168), bleibt offenbar nur der Rekurs auf den menschlichen Willen. Dieser liegt jedoch auch dem ,hypothetischen Imperativ und anderen, weniger anspruchsvollen Formen des Müssens und Sollens zugrunde, sowie der von Menschen errichteten Sanktionierung. Deshalb kann es für Sanktionisten naheliegen zu glauben, 
der Wechsel von einer Kantianischen Vernunftbegründung zu einer Begründung im Wollen bestätige ihre These. Doch das ist kurzschlüssig. Was für die Begrïndung von Sollensansprüchen gelten mag, muß explikativ noch keine Bedeutung haben. Auch wer Kants ,kategorischen Imperativ" oder schwä-

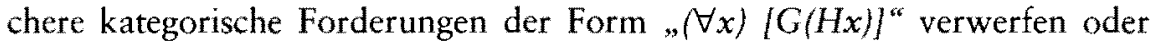
anders begründen will als er, muß schließlich wissen, was er negiert bzw. erhärtet. Der Sinn des Müssens, ausgedrückt im deontischen Modaloperator „G", kann eben auch dann, wenn man meint, ihn sanktionistisch reduzieren zu können (S. 176), nicht einfach mit einer bestimmten, wie immer gearteten Antwort auf die Begründungsfrage gleichgesetzt werden.

Nun kann man, losgelöst von dieser Verwirrung, sehr wohl dafür argumentieren, daß auch die Sinnfrage letztlich auf den Willen zurückführt (Abschnitt 9). Dennoch wäre es ein fataler Kurzschluß anzunehmen, daß dieser Wille sich nur auf die Sanktionierung beziehen kann. Im Gegenteil, eine solche Beschränkung wäre absolut implausibel. Nehmen wir an, eine Gruppe von Menschen (z.B. ein Verein) verständigt sich einvernehmlich auf eine kategorische, an alle Mitglieder adressierte Verhaltensregel (z.B. Präsenzpflicht bei allen Veranstaltungen). Wäre es dann nicht äußerst merkwürdig anzunehmen, daß der gemeinsame Wille, der dieser Regel zugrundeliegt, sich nicht auch und zuallererst auf ihre Erfüllung richtet? Selbst wenn man (kontrafaktisch, S. 163 Anm. 21) voraussetzen könnte, daß sie sich ohne gleichzeitige Sanktionierung (z.B. Strafzahlungen an die Vereinskasse bei Nichterscheinen) nicht in Kraft setzen läßt, wäre die Leugnung des primären, die Regelbefolgung betreffenden Willensinhaltes grotesk. Und würde sich daran prinzipiell etwas ändern, wenn man den Kreis der Adressaten vergrößert und den Inhalt der Regel abstrakter faßt (wie im, kategorischen Imperativ" Kants) oder wenn man die Willensfundierung nicht mehr (wie bei der Vereinsregel) direkt, explizit und konsensuell sein läßt, sondern mit der gesamten, komplexen Vielfalt sozialer Willensbildungsprozesse rechnet? Natürlich nicht. Vielmehr läßt gerade die Wendung von einer Vernunft- zur Willensbegründung die Skepsis gegenüber dem Sanktionismus, statt sie zu reduzieren, noch einmal massiv anwachsen. Denn da der menschliche Wille ja auch den schwächeren Formen des Sollens zugrundeliegt, die nicht sanktionistisch expliziert werden sollten (S. 179), erscheint es nun doch viel plausibler, ihn unter Wahrung begrifflicher Einheit schon beim Gattungsbegriff des Sollens ins Spiel zu bringen und für die stärkeren Formen allenfalls einen nicht explikativen, spezifikatorischen Sanktionismus ins Auge zu fassen (S. 164f.). 


\section{Woran können Sollensansprüche scheitern?}

Dieser Gedanke läßt sich erhärten, wenn man unvoreingenommen danach fragt, was es heißen kann, daß ein Müssen oder Sollen, ergeht' bzw. ,besteht'. Verschiedene Gesichtspunkte kreuzen sich hier. Um sie zu trennen, empfiehlt sich ein negatives Verfahren, bei dem schrittweise geprüft wird, warum ein erhobener Anspruch scheitert. Ein einfaches Beispiel dient als Leitfaden. Angenommen, ich treffe jemanden, der in ernsthaftem Ton zu mir sagt: „Gib mir $10 €$ !" oder „Du mußt mir $10 €$ geben. " Das ist offenbar eine kategorische Forderung der Form „G(Hx)", die mich in die Position von „x" gerückt hat. So fasse ich sie auch auf. Aber hat sie schon deshalb „Bestand" und verpflichtet mich etwa, $10 €$ an den Redner zu zahlen? Sicher nicht. Aber wenn nicht, warum nicht? Womit kann ich meine Zahlungsverweigerung untermauern?

8.1 Ich kann so tun, als hätte ich den Redner gar nicht gehört, verstünde kein Deutsch oder fühlte mich nicht von ihm angesprochen. Dann werde ich reaktionslos bzw. mit einer kurzen, abweisenden Gebärde an ihm vorbeigehen. Aber damit schaffe ich seine Forderung nicht aus der Welt. Sie existiert, und zwar allein deshalb, weil er sie erboben hat, auch wenn ihr nicht mehr zugrundeliegt als sein an mich gerichteter Wunsch oder Wille. Natürlich muß ich ihm nicht gehorchen oder mich zum Gehorsam verpflichtet fühlen. D.h. ich kann prinzipiell unterscheiden zwischen einer (grundlosen oder begründe$\operatorname{ten}^{56}$ ) bloßen Forderung, die jemand mir gegenüber erhebt, und einer berechtigten oder legitimen Forderung. Auch eine bloße Forderung aber bleibt eine Forderung. Sie setzt also keineswegs voraus, daß die fordernde Person dazu legitimiert ist oder gar „etwas in der Hand haben“ und „über gewisse Machtmittel verfügen “ muß, geschweige denn ihre Forderung ,immer mit der Androhung von Übeln für den Fall des Zuwider-Handelns verbinden kann" ${ }^{\text {". }}{ }^{7}$

56 Begründetheit ist nicht gleichbedeutend mit Berechtigung oder Legitimität. Auch der nicht legitimiert Fordernde kann mehr oder weniger gute Gründe für seine Forderung haben und sie nur deshalb stellen. So könnte mein Gegenüber gerade ausgeraubt worden sein und dringend Telefongeld benötigen. Oder er möchte vielleicht nur eine Wette des Inhalts gewinnen, daß er sich traut, einen Fremden in dieser brüsken Form anzusprechen, wohl wissend, daß dieser ihm kein Geld geben wird.

57 Stemmer (2000) 50. Implausibel sind solche Behauptungen auch dann, wenn man sie nicht im explikativen, sondern nur im spezifikatorisch sanktionistischen Sinne liest (S. 164, Anm. 23). Allenfalls für die Rede vom ,Befeblen', ,Kommandieren' und ,Anordnen', nicht aber für die vom ,Fordern' erscheint ein sanktionistisches Zusarzkriterium erwägenswert. Und auch dem steht der Sprachgebrauch oft entgegen. Selbst der dezidierte spezifikatorische Sanktionist Austin $\left(1832,{ }^{5} 1885,21\right)$ hat dies indirekt anerkannt, wenn er erklärt, ein bloßer Wunsch ohne realen "Befehlscharakter' lasse sich sprachlich mühelos in der Befehlsform ausdrükken, so wie umgekehrt ein realer ,Befehl' als Bitte. Zugleich verdeutlicht er mit einem einschlägigen Tacitus-Zitat, daß es sich dabei nicht etwa um Neuerungen oder Besonderheiten der englischen (bzw. deutschen) Sprache handelt. 
Begriff und Existenz des Forderns sind, wie das Beispiel zeigt, von Sanktionen vollkommen unabhängig. Es nützt auch nichts, dagegen einzuwenden, als nicht Legitimierter ohne Drohpotential hätte mein Gegenüber eigentlich nur eine Bitte, also einen viel schwächeren Sollensanspruch, an mich richten können und besser daran getan, dies auch verbal zum Ausdruck zu bringen. Sicherlich. Aber er hat nun einmal, so wie das Beispiel konstruiert ist, nicht die verkehrsübliche (und auch für ihn wahrscheinlich effektivere) Bittform gewählt, sondern mich brüsk und unmißverständlich aufgefordert. Er bedient sich dabei der Semantik der Umgangssprache, die auch der interessierte Philosoph nicht einfach abschaffen, sondern allenfalls für seinen Idiolekt stipulativ abändern kann (vgl. S. 164).

8.2 Im übrigen stehen auch schwächere Sollensansprüche unter gewissen Legitimierungserfordernissen. Sie sind nur dann berechtigte und nicht nur bloße Ansprïche, wenn ihre Adressierung legitim ist. Nehmen wir an, mein Gegenüber hätte die übliche Höflichkeit walten lassen und nur gesagt: „Entschuldigen Sie bitte, würde es Ihnen etwas ausmachen, mir kurzfristig mit $10 €$ auszuhelfen?" Verpflichtet bin ich auch dadurch nicht, normalerweise aber geneigter. Dennoch könnte ich ihn, wenn ich mich ungehobelt verhalten will, brüsk abblitzen lassen: „Haben wir vielleicht schon einmal miteinander Schweine gehütet? “ Ich weise dann nicht nur seine Bitte zurück, sondern schon seinen Anspruch, als Fremder überhaupt in einer Position zu sein, Bitten an mich adressieren zu können. Das ist unhöflich, unsozial und vielleicht sogar unmoralisch, vorausgesetzt die bloße Zugehörigkeit zur Menschengemeinschaft verleiht jedem Menschen die ,Würde' bzw. das Recht, sich zumindest mit Bitten und anderen elementaren kommunikativen Akten an andere Menschen wenden zu dürfen. Dies entspricht gewiß nicht dem Verständnis des „Übermenschen" oder des radikalen "moralischen Skeptikers" (Anm.16), wohl aber unserem gewöhnlichen Selbstverständnis. Ja, die meisten von uns würden sich nicht einmal herzlos von einem Hund abwenden, der uns, um Hilfe bittend" seine verletzte Pfote entgegenstreckt. Dennoch bildet die Legitimiertheit des bloßen Adressatenverhältnisses ein erstes, elementares Kriterium, an dem selbst schwache Sollensansprüche scheitern können und stärkere natürlich erst recht. ${ }^{58}$ Auch dieses Kriterium ist von Sanktionen prinzipiell unabhängig

58 Besonders deutlich ist das bei fremden Moral- und Rechtssystemen. Ein Kulturanthropologe versteht natürlich, welche Handlungen innerhalb eines Stammes verboten und mit sozialer Achtung (S. 159) verhunden sind. Aber er wird sich davon genausowenig persönlich betroffen und angesprochen fühlen wie ein Rechtshistoriker, der die Strafgesetzteile des, Codex Hammurabi' studiert. Auch gegenüber der eigenen Moral- und Rechtsgemeinschatt gibt es diverse Möglichkeiten zur Selbstdistanzierung und entsprechenden Bestreitung legitimer Adressatenschaft. In multikulturellen Gesellschaften springt das sofort ins Auge, gilt aber auch hei stärkerer kultureller Geschlossenheit, vorausgesetzt die Individuen sind frei und personal stark genug, um sich nicht völlig von sozialen Ansprüchen vercinnahmen zu lassen (vgl. Anm, 9, 16,67). 
und betrifft nur die Legitimität, nicht die Faktizität und den Begriff des Sollens.

8.3 Auch die Berechtigung der Adressierung garantiert natürlich nicht die des erhobenen Anspruchs selbst. Einem Freund, der $10 €$ von mir verlangt, kann ich mich als Adressat kaum entziehen, bin dadurch aber noch nicht verpflichtet, ihm zu entsprechen. Selbst wenn er bittet, ganz gewiß jedoch wenn er fordert, kann ich berechtigterweise fragen, warum. Ist sein Ansinnen nachvollziehbar, werde ich mich als Freund auch verpflichtet fühlen, es zu erfüllen. Darin unterscheidet sich dieser Fall von dem ansonsten gleichgelagerten Fall eines Fremden, den ich als legitim Bittenden anerkenne. Freundespflichten und andere Pflichten, die in persönlichen Beziehungen (Verwandtschaft, Kollegialität etc.) gründen, sind eben unbestreitbare Pflichten. Deshalb korrespondieren ihnen auch Rechte, die Freunde (Verwandte etc.) legitim geltend machen. Töricht wäre es, dies zur Rettung sanktionistischer Ideen abzustreiten oder darauf zu insistieren, daß die im Weigerungsfalle naheliegende, sozialpsychologisch, natürliche“ Erschütterung der Beziehung bis hin zur gänzlichen Zerstörung eine ,Sanktion' sei (S. 171). Auch legitime Forderungen, die in persönlichen Rechten und Pflichten gründen, sind normalerweise nicht sanktionenbewehrt. Aber natürlich sind reine Persönlichkeitspflichten relativ schwache Pflichten. Es gibt stärkere, und zwar nicht nur auf der gesamtgesellschaftlichen Ebene, sondern auch im persönlichen und privaten Bereich.

8.4 Wenn mein Freund mich auf meine Warum-Frage hin zu Recht daran erinnern kann, daß ich $10 €$ von ihm geliehen bzw. ihm $10 €$ für heute versprochen habe oder daß dies der Fälligkeitsbetrag aus einer von mir verlorenen Wette ist, hat er offenbar mehr, in der Hand'. Doch wieviel mehr? Sanktionen spielen weiterhin keine Rolle, normalerweise jedenfalls. Denn Versprechungen, Wetten, Anleihen, Tauschgeschäfte und andere Transaktionen unter Freunden verzichten im allgemeinen auf Absprachen (geschweige denn institutionelle Vorkehrungen) über Belohnungen oder Strafen bei Erfüllung bzw. Verletzung und auf rechtsrelevante Maßnahmen zur Beweissicherung (schriftliche Verträge, Quittungen, Zeugen). Würde ich also wahrheitswidrig behaupten, ich hätte das Geld nicht geliehen, sondern geschenkt bekommen, könnte mein Freund mich kaum zwingen, die $10 €$ herauszurücken. Was seiner Forderung mehr Gewicht verleiht als das bloße Freundesrecht, ist nur die Tatsache, daß meine Weigerung auch übergeordnete soziale Institutionen tangiert, die als Voraussetzung jeder Gemeinschaft gelten, allen voran das Versprechen. Als einschlägig sozialisiertes Wesen (Anm. 16) werde ich diese Verpflichtung nicht nur als eine persönliche, sondern auch als eine moralische auffassen, die normalerweise durch interne Sanktionen (erwartbare Gewissensbisse und Schamgefühle, S. 159) gestützt wird. Doch diese Sanktionierung konstituiert nicht mein konkretes Gefordert- oder Verpflichtetsein und ist allemal keine, die mein Freund gegen mich appliziert. Ebenso ist die Wahrscheinlichkeit, 
daß ich seine Freundschaft verliere, zwar bei nicht eingehaltenen expliziten Versprechen und Vereinbarungen erwartbar größer als bei ad hoc verweigerten Freundesdiensten, tritt aber nicht in jedem Falle ein ${ }^{59}$ und wäre als eine sozialpsychologisch, natürliche' Folge ebenfalls keine Sanktion.

8.5 Private Versprechen oder Verträge werden erzwingbar, wenn sie in einem rechtlichen oder rechtsähnlichen Rahmen stehen. Habe ich meinem Freund einen Schuldschein ausgestellt oder verfügt er über verläßliche Zeugen, kann er mich, wenn er möchte, genauso vor Gericht auf Rückerstattung verklagen wie ein professioneller Geldverleiher. ${ }^{60}$ Dann hat er buchstäblich ,etwas in der Hand" gegen mich, das seine Forderung stützt und mir ihre Zurückweisung nicht nur subjektiv, als moralisch sozialisierte Person und Freund, sondern als Mitglied der Rechtsgemeinschaft objektiv schwierig macht. Sanktionen können daran beteiligt sein, müssen es aber nicht. Entscheidend ist nur die Durchsetzbarkeit berechtigter Ansprüche, wofür diverse Maßnahmen zur Verfügung stehen, im gegenwärtigen Fall vor allem restitutive (Abschnitt 5.4). Und selbst wo Sanktionen im Spiel sind, können auch legitimierte Sollensansprüche praktisch immer noch scheitern. Nicht jeder eben, der Recht hat, bekommt sein Recht. Nur Maßnahmen, die im Bedarfsfalle konsequent umgesetzt werden, können restitutive (oder auch abschreckende, reformative und objektiv hindernde) Wirkung entfalten und sekundär (S. 172f.) sanktionierend werden.

Geschicht dies (z.B. korruptionsbedingt, Anm. 28) selten oder so willkürlich, daß das gesamte Verfahren unberechenbar wird, gerät mit der

59 Keine Gemeinschaft hätte Bestand, gäbe es keinerlei verläßliche Versprechen, Verabredungen oder Verträge, und eine (Kantianisch) generalisierte Maxime, sie nach Belieben zu brechen, wäre auch selbstaufhebend. Doch daraus folgt nicht, dafs ein hinreichender Grad der Verläßlichkeit nur erreicht wird, wenn die Einhaltung lückenlos ist oder Verletzungen sanktioniert werden. Ein einziges nicht eingehaltenes Versprechen wird meinen Freund wohl zurückhaltender gegenüber meinen Bekundungen machen, aber noch nicht zum Bruch der Freundschaft veranlassen. Dazu bedarf es gewöhnlich mehr. Umgekehrt kann schon ein gravierender, exemplarischer Einzelfall ausreichen, um eine Beziehung fundamental zu erschüttern. Das gilt nicht nur beim Bruch von übergeordneten sozialen Institutionen, sondern sogar bei Persönlichkeitspflichten. Die brüske Verweigerung eines erbetenen, leicht zu erfüllenden Freundschaftsdienstes kann eben u.U. auch ein Zeichen sein, daß etwas grundsätzlich mit dieser Beziehung nicht stimmt, und deren definitives Ende einläuten. Daß sich all dies normalerweise weit unterhalb der Ebene von relevanten, wechselseirigen Sanktionierungen abspielt, muß kaum erwähnt werden.

60 Ich konzentriere mich auf diesen besonders klaren und einfachen Fall, der als Beispiel genügt. Varianzen und Komplikationen bei den Beweismitteln, Durchsetzungsverfahren oder Verpflichtungsterhältnissen (vgl. dazu S, 192, Anm. 66 und S. 194, Anm. 68) bleiben ausgeklammert. Ebenso sehe ich zur Vereinfachung davon $a b$, daß es auch unterhalb der Ebene staatlicher Gerichtsbarkeit zahlreiche rechtsähnliche Formen der Durchsetzbarkeit von legitimen Ansprüchen gibt. Die Übertragbarkeit der relevanten Prinzipien auf diese Bereiche (Familie, Firma, Verein u.a.) ist offenkundig. 
Durchsetzbarkeit auch das Rechtssystem selbst in Gefahr, ebenso andere rechtsähnlich organisierte soziale Normensysteme. Daher wird von historischer und sozialwissenschaftlicher Seite, aber auch in der Philosophie ofter gesagt, die faktische Strafpraxis im Falle von Normenverletzungen sei das Kriterium dafür, ob eine Norm mit verpflichtendem Charakter sozial ,etabliert" ist oder, gilt ${ }^{6}{ }^{61}$ Doch in dieser Pauschalität ist das zu ungenau und mehrfach mißverständlich. Denn erstens ist die faktische Umsetzung immer nur eine Sache des sozial erwünschten bzw. zur Stabilisierung benötigten Grades und betrifft nicht nur Strafen, sondern auch Belobnungen. ${ }^{62}$ Zweitens ist sie nur dort erforderlich, wo die Motivationskraft der Normen nicht hinreicht, um den erstrebten Konformitätsgrad sicherzustellen, kann also bestenfalls einen motivationalen Sanktionismus in der schwächeren der beiden erwähnten Versionen stützen (\$. 163). Und auch das ist keineswegs ausgemacht, da dieses Ziel ja nicht nur durch Sanktionen befördert wird, sondern auch durch andere Maßnahmen. Vor allem aber muß, drittens, Klarheit darüber bestehen, was eine defiziente Durchsetzungspraxis in Frage stellt und was nicht. Gefährdet ist nur die ,Etabliertheit' und ,soziale Geltung' rechtlicher oder rechtsähnlicher Normen. Das mag für Historiker und Soziologen hinreichen, um sie so zu behandeln, als wären sie faktisch inexistent. Philosophen und Psychologen aber können sich damit nicht begnügen. Denn daß eine Forderung sozial nicht durchsetzbar ist, heißt eben nicht, daß sie unberechtigt wäre, geschweige denn als Anspruch gar nicht ergangen.

\section{Willensfundiertes Sollen}

Die Diagnose der Gründe, aus denen Sollensansprüche scheitern können, hat verschiedene Kriterien hervortreten lassen, von denen es abhängt, ob sie ,ergangen' sind und ,Bestand' haben. Das sind insbesondere: (A) das Erheben bzw. Ergehen des Anspruchs selbst, (B) seine Berechtigung im Blick auf (B1) Adressierung und bestehende (B2) persönliche oder (B3) übergeordnete soziale Bindungen und (C) seine faktische Durchsetzbarkeit bri den Adressaten. Diese Kriterien sind prinzipiell voneinander unabhängig $\mathrm{u} \cdot \mathrm{d}$ frei kombinierbar, im Regelfall jedoch so miteinander verknüpft, daß (C) nur auf der Basis von (B) und (B) nur auf der Basis von (A) in Funktion treter. ${ }^{63}$ Sanktionen, so hat sich

61 So z.B. Locke: An Essay Concerning Human Understanding, 1, 3,12; Sidgwick (71907) 29; Kelsen ( $\left.{ }^{2} 1960\right)$ 10f, 48, 122; (1946) 26, 42, 62; Hart (1961) 82; Tugendhat (1984) 74f., 133; (1993) $19 ;(1997) 14$.

62 Vgl. dazu noch einmal die Abschnitre 1-2, sowie S. 176f., Arum. 45 und Arm. 38, 58-59.

63 Die menschliche Wirklichkeit ist komplexer. Auch Sollensansprüche, die (z.B. aus Unwissenheit, Angstlichkeit oder Resignation) nicht erhoben werden, können berechtigt sein bzw. unberechtigte Ansprüche durchsetzbar, wenn die Machtverhältnisse dies gestatten. Denkbar 
gezeigt, spielen erst bei (C) eine signifikante Rolle und auch das keineswegs immer, sondern nur in einer speziellen Gruppe von motivational defizienten Fällen. Diese Fälle kann man, wenn man will, nach dem Prinzip des spezifikatorischen Sanktionismus aussondern (vgl. S. 164f.). Nichts spricht allerdings dafür, daß dies auch jenseits eines mehr oder weniger trivialen Kernbereichs sinnvoll ist. Ein motivationaler Sanktionismus jedenfalls, gleichgültig ob in der stärkeren oder schwächeren Version, geschweige denn ein konsequenter (moderater oder gar radikaler) explikativer finden keinerlei Anhalt an den Kriterien, die Ansprüche des Sollens und Müssens scheitern lassen.

9.1 Konstitutiv für den Begriff des Sollens ist nur das basale Kriterium (A). Wenn impersonale Ansprüche außer Betracht bleiben (S. 168, 184f.), kann die Tatsache, daß ein Sollensanspruch ergeht, aber offensichtlich nichts anderes heißen, als daß eine Person etwas will und dies adressiert an andere äußert. Dabei kann die ,Person' ein Individuum sein, aber auch eine Gruppe, Korporation oder Institution, die einen gemeinsamen Willen entwickeln, sei es direkt mit Beteiligung aller Träger oder indirekt, vermittelt durch Repräsentanten. ${ }^{64}$ Der Willensinhalt wiederum kann eine partikuläre Handlung sein oder ein einzelner Sachverhalt, der aktiv zu realisieren ist, aber natürlich auch die Erfüllung einer moralischen, rechtlichen oder sonstigen Norm oder Regel (S. 183f.). Adressaten und Personen können zusammenfallen. Beispiele hierfür aus dem sozialen Bereich liefern Verhaltensregeln oder Statuten, die sich die Mitglieder von Gruppen selber geben (S. 185), oder auch (idealiter) die Gesetzgebung in einem demokratischen Staat. Den elementarsten Fall aber liefert das Wollen einzelner Menschen. Denn obwohl sich Willenshaltungen nicht einfach, wie in der Literatur z.T. behauptet, auf Imperative reduzieren lassen,

bleibt sogar, bestimmte Ansprüche mit Hilfe von Sanktionen oder anderen Maßnahmen durchzusetzen bzw. zu erzwingen, ohne daß die Betroffenen aufgefordert oder auch nur mit den relevanten Standards bekannt gemacht werden (vgl. Anm. 30 und 36). Damit wäre Krjterium (C) nicht nur von (B), sondern auch von Kriterium (A) entkoppelt. Das ist die Regel, wenn Tiere, die über keine Vorform planender Überlegung verfügen (vgl. jedoch \$. 157, Anm. 6, S. 170, Anm. 31), von Menschen, ,mit Zuckerbrot und Peitsche' abgerichtet werden. Bei Kindern, geschweige denn eruachsenen Menschen ist ein derart rüdes, barbarisches Vorgehen zum Glück ungebräuchlich. Möglich wäre es allerdings. So könnte man die Hobbesianische, durch Kelsen weiterentwickelte Idee von Strafgesetzen, die nur an die Staatsbeamten adressiert sind (vgl. S. 166, Anm. 26-27), dadurch zusätzlich radikalisieren, daß man auf jede Bekanntmachung an die Bürger verzichtet. Wenige Sympathisanten des (explikativen) Sanktionismus dürften in praxi so weit gehen wollen, könnten theoretisch aber eigentlich nichts dagegen haben. Und Kelsen zumindest $(1946,43 \mathrm{f} ., 72 \mathrm{ff}$.$) ist denn auch nicht davor$ zurückgeschreckt, dem alten Rechrsgrundsatz "ignorantia juris neminem excusat" diesen barbarischen Sinn zu unterlegen.

64 Năheres zu den hier angesprochenen Formen überindividueller Willensbildung findet man in Seebaß (2001) 79-99. 
sind sie doch vom Begriff her, genauso wie assertorische Behauptungen oder Meinungen, mit einem intrinsischen, reflexiven ,Aufforderungscharakter ${ }^{6}$ und daher per se mit einem (,selbstadressierten') Sollensanspruch verbunden. ${ }^{65}$ Wer etwas will, beansprucht im Kern, daß es ,der Fall sein möge', und ist ebendamit, gleichgültig wie groß die Realisierungs- und Handlungsdistanz zwischen Wollen und Gewolltem ist, primär selbst aufgefordert, Sorge zu tragen, daß es verwirklicht wird. Darauf wiederum bauen die diversen, komplexen Willensbildungsprozesse auf, die soziale Sollensansprüche und Normen fundieren, einschließlich rechtlicher und moralischer. Dem kann hier nicht weiter nachgegangen werden. Prinzipiell jedenfalls findet die Frage nach dem Woher eines nicht sanktionistisch interpretierten Sollens (S. 179) mit dem Rekurs aufs Wollen eine natürliche, naheliegende Antwort, die zugleich den Vorteil hat, daß sie die konzeptionelle Einheit der verschiedenen Formen des Sollens wahrt (S. 165, 179, 185).

9.2 Solange Adressaten und Personen, die einen Sollensanspruch erheben, zusammenfallen, kommt die Frage nach dessen Berechtigung normalerweise nicht auf, ganz besonders in elementaren, intra-individuellen Fällen. ${ }^{66}$ Dann kann man sagen, daß zusammen mit (A) auch Kriterium (B) erfüllt ist und der Adressat nicht nur aufgefordert, sondern verpflichtet. Deshalb spielt auch die Differenzierung zwischen verschiedenen, mehr oder weniger starken Formen des Sollens hier zunächst keine entscheidende Rolle. ${ }^{67}$ Das ändert sich natür-

65 Eine detaillierte Analyse und explikative Rechtfertigung dieses Willensbegriffs findet man in Seebaß (1993 a) Kap. IV-V. Auf sie kann hier nur verwiesen werden. Zur Kritik einer rein ,imperativischen Theorie' des Willens, die sich bis zu Augustin zurückverfolgen läßt und z.T. auch in der Analytischen Philosophie vertreten wird, vgl. speziell a.a.O., 266 Anm. 121 und 276f. Anm. 142.

66 Bei Kollektiven ist dieser ,Normalfall' allerdings nur gegeben, wenn die gemeinsame Willensbildung direkt und konsensuell erfolgt (wie im Vereinsbeispiel, S. 185), während sich sonst notorisch schwierige Probleme der Verfahrenslegitimität anschließen; vgl. dazu Seebaß (2001) 90ff. Auch bei Individuen kann die Berechtigung zum Problem werden, besonders wenn Zweifel bestehen, ob bzw. wie weit der Teil der Person, der den Anspruch erhebt, als personal identisch mit dem adressierten Teil gelten kann (vgl. S. 170, Anm. 32). Von solchen Komplikationen wird hier abgesehen.

67 Das gilt allerdings nur, solange keine Sollenskonflikte bestehen. Wenn mehrere berechtigte Ansprüche konfligieren, kann deren relative Stärke bedeutsam für ihre Abwägung werden. In kodifizierten Normensystemen, die solche Komplexionen in Rechnung stellen, ist dies z.T. ausdrücklich vorgesehen, wie im „rechtfertigenden Notstand“ des deutschen Strafrechts $(\mathbb{S} 34 \mathrm{StGB})$. Gäbe es so etwas wie eine umfassende, quantifizierbare und linear geordnete ,Rangliste“ geschützter Rechtsgüter und korrespondierender Pflichten, könnte man daraus Kriterien auch für die Differenzierung verschiedener Grade des Sollens gewinnen. Unsere rechtliche und moralische Praxis ist davon weit entfernt. Es ist auch wenig wahrscheinlich, $\mathrm{da}$ 的 überhaupt komplexe, praktikable Normensysteme geben kann, die Inkommensurabilität und Äquidistanz zwischen konfligierenden Forderungen prinzipiell ausschließen. Scharfe Grenzen und Skalierungen sind daher kaum zu erwarten. 
lich, wenn fremde Adressaten im Spiel sind, deren Willenseinstimmung zweifelhaft ist. Nun treten (A) und (B) nicht nur konzeptuell, sondern faktisch klar auseinander. Der Gattungsbegriff des Sollens ändert sich jedoch nicht, er wird nur spezifiziert durch variable Antworten auf die Berechtigungsfrage. Wer z.B. weiß, daß sich die Legitimität seines erklärten Willens, ein anderer möge Sorge tragen, daß etwas bestimmtes der Fall ist, bestenfalls aus der vorausgesetzten allgemeinmenschlichen Kommunikativität ergibt (S. 187), wird dies normalerweise auch verbal zu erkennen geben und seinen Anspruch nicht als Befehl, sondern als Bitte vortragen. Wer einen Ratschlag erteilt, wird stärkere Formulierungen wählen. Denn er kann sich (z.B. als Arzt, S. 181) zusätzlich dadurch legitimiert sehen, daß er vom Adressaten selbst gefragt wurde und seinen Rat auf dessen erklärten oder vermuteten Willen und (unterstellte) Rationalität abstimmt. Weil Menschen aber konkurrierende Interessen haben und ihre Ziele bzw. ihr Vertrauen in befragte Ratgeber angesichts des Ergebnisses ändern können, dürfte auch er sich zunächst des Befehlstons enthalten und sich nicht einbilden, daß sein wohlmeinender, rationaler Rat den Adressaten unbedingt zur Befolgung verpflichtet. Darin unterscheidet der bloße Ratgeber sich von einem legitimierten Vorgesetzten oder von jemandem, der sich nur als Vermittler objektiv geltender Normen versteht oder ein kategorisches Gebot aus Prämissen, die (kontextuell, S. 182 Anm. 52) nicht mehr zur Disposition stehen, praktisch-syllogistisch ableitet.

Die eingehendere Untersuchung der verschiedenen Arten der Legitimierung und der Berechtigung von Sollensansprüchen kann nicht mehr Gegenstand dieses Aufsatzes sein. Offen bleibt auch die weitergehende Frage, ob alle legitimierbaren Ansprüche und Verpflichtungen nur im menschlichen Willen gründen oder ob auch nichtvolitionale, naturrechtliche oder, rein vernünftige' Rechtfertigungsgründe anzuerkennen sind. Festzuhalten bleibt aber in jedem Fall, daß die Stärke des Sollens bzw. der Grad der Verpflichtung sich zentral nur nach Art und Umfang ihrer Berechtigung bemessen (nicht etwa

Noch mehr gilt dies für das konfligierende, willensfundierte Sollen von Individuen. Diese müssen sich ja (zumindest in modernen Gesellschaften) immer an verschiedenen, legitimierten Regel- und Normensystemen nebeneinander orientieren und haben zugleich vielfaltige eigene Ansprüche, die in sich keineswegs homogen sind. Hier wäre es vollends illusionär, mit vorgegebenen ,Ranglisten' oder fixierten, klar kalkulierbaren persönlichen ,Präferenzierungsindizes" (o.a.) zu operieren, die z.B. dem einzelnen Wähler die Entscheidung darüber abnehmen könnten, welches Gewicht er dem Anspruch von formal korrekt zustandegekommenen Gesetzen, die ihm moralisch bedenklich erscheinen, persönlich geben will (vgl. Anm. 58), oder auch nur darüber, wie weit er sich durch seine eigenen früheren Vorsätze (Anm. 32) bzw. seine präsenten, widersprüchlichen Willensregungen gebunden fühlen soll, einschließlich solcher, die auf die Vermeidung bzw. Gewinnung gesetzter Sanktionen abzielen. Das irreduzibel dezisionistische Element normaler, konfliktorientierter Willensbildungsprozesse zeigt einmal mehr, wie hoffnungslos jeder Versuch wäre, Bestand und Stärke des Sollens bzw. Müssens rein sanktionistisch explizieren zu wollen. 
nach ihrer Durchsetzbarkeit oder gar Sanktioniertheit) und daß dies auch die umgangssprachliche Differenzierung zwischen ,bloßem Sollen', ,Müssen“ oder ,Verpflichtetsein' prägt. $^{68}$

9.3 Mit der Einführung von Kriterium (C) verstärkt sich also nicht die Verpflichtung, sondern allein die Durchsetzbarkeit und mit ihr der Konformitätsdruck bzw. die faktische Konformität mit bestehenden Sollensansprüchen, einschließlich solcher, die unberechtigt sind und überhaupt nicht verpflichten (Anm. 63). Das gilt natürlich auch, wenn Sanktionen im Spiel sind. Gewiß, die Sanktionierung konstituiert ein Sollen eigener Art. Sie bezieht sich ja auf den Willen des Adressaten, die eingeführten Strafen zu vermeiden bzw. Belohnungen zu gewinnen. Aber zum einen ist der daraus abzuleitende Anspruch normalerweise (außer bei extrem hohen, erpresserischen Sanktionen) nicht stärker als der eines anderen, nicht kategorisch verpflichtenden prudentiellen Rats, den die Adressaten gegen ihre übrigen Interessen abwägen müssen. Und zum anderen hat dieses sanktionskonstituierte Sollen (losgelöst von der heroischen Kaufpreis-Deutung, S. 179) nichts mit dem basalen, auf Erfüllung gerichteten Sollensanspruch zu tun, um den es primär geht (S. 185). Ob und mit welchem etwaigen Legitimierungshintergrund sich dieser zentrale Anspruch, gestützt auf die Kriterien (A) und (B), nur als ein ,bloßes Sollen' erweist oder als ein ,verpflichtendes Müssen', ist von Bestand und Stärke des sanktionskonstituierten Sollens vollkommen unabhängig. Und auch das letztere bestätigt im übrigen nur die Richtigkeit unseres Gattungsbegriffs. Denn selbst wer sich ausschließlich durch die Sanktionierung gefordert füh-

68 Die Umgangssprache ist hier allerdings sehr flexibel, da es eben zahllose Arten und Grade relevanter ,Berechtigung* und diverse Möglichkeiten zu ihrer Spexifizierung gibt (vgl. schon Anm. 57). Auch die Rede von, Pflichten' oder vom, Verpflichtetsein" der Adressaten ist weit. Sie bezieht Persönlichkeitspflichten (S. 188) und partikulare Pflichten bzw. intra-individuelle ,Pflichten gegen sich selbst ${ }^{*}$ (vgl. S. 170, Anm, 32, S, 192, Anm. 66) ebenso ein wie Pflichten, die nicht als menschengemacht und menschlich veränderbar gelten, sondern als vorgegeben (vgl. S. 168, 184f.). Und auch wo der Wille des Verpflichteten direkt oder indirekt zur Legitimierung beiträgt, rechnet sie mit vielfältigen Formen und Gradstufen, zumal bei Willenskonflikten (Anm. 66-67). Rechtspflichten oder moralische Pflichten, die alle Mitglieder einer Gemeinschaft angehen und als uneingeschränkt bzw. uneinschränkbar legitimiert gelten (S. 183f.), bleiben ein Sonderfall, genauso wie spezifizierte Pflichtbegriffe, bei denen neben der Legitimierung auch die Durchserzbarkeit bzw. Sanktioniertheit Teil der Bedeutung sind. Die bloße Ableitung aus dem Willen der Adressaten reicht normalerweise allerdings nicht aus, um die Rede von ihrer, Verpflichtung ${ }^{*} z$ rechtfertigen, da dies z.B. auch in illegitim erpresserischer Weise geschehen kann. Die Rede vom, Müssen* ist weniger restriktiv. Sie erstreckt sich auch auf die Ergebnisse erpreßter, unfreier Willensbildung (vgl. S. 174f., Anm. 39-40) und auf nicht verpflichtende Ratschläge oder Empfehlungen (S, 181f.). Das liegt z.T. an bestehenden impliziten Kontextbeschränkungen, ofter aber wohl noch an der modalen Ambiguität prudentiell-hypothetischer Muß-Säze (Anm. 51). Hier hat man deshalb besonders sorgfältig auf begriflliche Differenzierung zu achten. 
len sollte, eine bestimmte Option zu ergreifen oder zu unterlassen, wäre ja nicht mit einem (illusionären) sanktionistischen ,Müssen' oder ,Sollen' der sanktionssetzenden Person konfrontiert, sondern nur mit dem intrinsischen Aufforderungscharakter seines eigenen Willens, negative Handlungsfolgen zu meiden und positive zu gewinnen. ${ }^{69}$

\section{Schlußbemerkungen}

Sanktionistische Theorien des Sollens, explikative zumindest, sind damit nicht nur negativ widerlegt, sondern auch positiv überholt durch ein konstruktives Gegenmodell. Dieses ist in der hier vertretenen Form (S. 191f., Anm. 65) eigenständig, an sich aber kein Novum, sondern nur eine Weiterentwicklung von Gedanken, die in der Philosophie seit langem präsent sind. Im wesentlichen entspricht es dem traditionellen System der normativen Verhaltenskontrolle (S. 178, Anm. 47), das insofern auch gegen Versuche verteidigt wird, es durch Modelle abzulösen, die aufgeklärter sein sollen, es in Wahrheit aber nur verständnislos simplifizieren.

Rückblickend kann man sich fragen, wieso eine konzeptionell so abwegige, hoffnungslose Idee wie der (explikative) Sanktionismus jemals Anziehungskraft gewinnen konnte. Nicht einmal externe Interessen antimetaphysischer oder naturalistischer Art, die sich mit ihm verbinden, kann er bedienen (Abschnitt 4). Ja, gerade die von seinen Sympathisanten kontrastiv favorisierte Begründung im menschlichen Willen hat sich als die erwiesen, die ihn prinzipiell scheitern läßt und positiv überholt (Abschnitte 7.3, 8-9). Unzureichende analytische Eindringlichkeit und mangelnde Differenzierung bei den Formen des Sanktionismus (Abschnitt 3) und den Begriffen der ,Sanktion' (Abschnitt 5) bzw. des, Sollens' selbst haben zweifellos dazu beigetragen, reichen zur Erklärung aber nicht aus. Man muß noch etwas tiefer ansetzen. Wie war es möglich zu übersehen, daß sich auch mit der kontraintuitiven

69 Auch wenn man nur Verpflichtungen ins Auge faßt, die sanktioniert und im menschlichen Willen begründet sind, muß man (wenigstens) vier verschiedene Arten des Wollens sorgfältig auseinanderhalten: (1) den Willen, der dem Anspruch zugrundeliegt, die Adressaten sollten bestimmte Standards erfüllen; (2) den Willen, ihre Erfüllung oder Verletzung zu sanktionieren; (3) den Willen der Adressaten zur Erreichung bzw. Vermeidung dieser Sanktionen und (4) ihren Willen, den geforderten Standards Genüge zu tun oder nicht. Der Fehler des Sanktionismus liegt nicht nur in der mangelnden Differenzierung von (1) und (2), sondern auch in der von (3) und (4). Deren Eigenständigkeit zeigt sich jedoch schon daran, daß die gewöhnliche, motivationsverstärkende Funktion von Sanktionen gerade darauf beruht, durch prudentielle Bezugnahme auf (3) einen internen Willenskonflikt zu schaffen, der geeignet ist, vermutete Konformitätsdefekte bei (4) im erwünschten Umfang zu unterdrücken. Außerdem hebt auch dieser Konflikt die Möglichkeiten zur freien Abwägung und Entscheidung nicht auf (vgl. S. 158, S. 161 Anm. 15, Anm. 67). 
Assimilation von Sanktionen an Kaufpreise (Abschnitt 6) und der Reduktion von Verpflichtungen auf das bloße Wissen darum, daß bestimmte Optionen absichtsvoll und berechtigterweise mit Sanktionen verbunden sind, nichts für den Sanktionismus gewinnen läßt, weil das Sollen bzw. Müssen auch hier nicht im Faktum der Sanktionierung liegt, sondern im Wollen der fordernden Personen und Adressaten?

Der Grund kann nur in Unklarheiten über den Willensbegriff bestehen, sowie im ungenügenden oder nur halbherzigen Sich-Einlassen auf die, mentalistischen' Verfeinerungen, die bei der Übertragung des behavioristischen Konditionierungsmodells auf den Menschen notwendig wurden (Abschnitt 2). Offenbar drückt den Sanktionisten die behavioristische Erblast. Wer sich nicht von der Vorstellung lösen kann, daß mentale Leistungen, wenn nicht ausschließlich, so doch in allen entscheidenden Hinsichten eigentlich, im Verhalten offen zutage liegen" und daß auch intentionale Zustände irgendwie kausaldispositionell zu verstehen sind (S. 155), kann die Phänomene des Wollens und der bewußten, überlegten Willensbildung und Handlungskontrolle nicht unvoreingenommen ins Auge fassen. Auch wo der Sanktionist die eklatantesten phänomenalen Verkürzungen des Behavioristen scheinbar hinter sich läßt, bleibt er wie dieser geneigt, äußere Begleitumstände, kausale Einflüsse und bloße Wirkungen intentionaler Einstellungen mit diesen selbst zu vermengen oder gänzlich an ihre Stelle zu setzen. Ihr nicht, naturalisierbarer" Möglichkeitsbezug (S. 168f.) und intrinsischer Aufforderungscharakter (S. 192) geraten so aus dem Blick. Und damit entgleitet auch der gemeinsame, volitionale Kernbegriff, der die verschiedenen Formen des praktischen Sollens und Müssens eint und der gerade dann konzeptionell unentbehrlich wird, wenn man außermenschliche (metaphysische, naturrechtliche o.a.) Fundierungen ablehnt. Da letzteres aber ein zentrales Interesse war, das sanktionistische Theorien befriedigen sollten (S. 168), ist diese Wendung nicht ohne Ironie. Es war eben (frei nach einem alten Werbeslogan) schon immer fatal, die Dinge etwas zu einfach haben zu wollen.

\section{Literatur}

Austin, J. (1832, $\left.{ }^{5} 1885\right)$, The Province of Jurisprudence Determined, repr. ed. W. E. Rumble, Cambridge 1995.

Baumann, J. / Weber, U. $\left({ }^{9} 1985\right)$, Strafrecht. Allgemeiner Teil, Bielefeld. Bentham, J. (1970), An Introduction to the Principles of Morals and Legislation, ed. J. H. Burns / H. L. A. Hart, London.

Buchanan, J. M. (1975), The Limits of Liberty, Chicago.

Hacker, P. M. S. (1973), Sanction Theories of Duty, in: A. W. B. Simpson (ed.),

Oxford Essays in Jurisprudence, 2 d. Series, Oxford.

Hart, H. L. A. (1961), The Concept of Law, Oxford. 
Hart, H. L. A. (1968), Punishment and Responsibility, Oxford.

Homans, G. C. (1961), Social Behavior. Its Elementary Forms, New York.

Kant, I. (1990), Eine Vorlesung über Ethik, ed. G. Gerhardt, Frankfurt.

Kelsen, H. (1946), General Theory of Law and State, Cambridge, Mass., repr. New York 1961.

Kelsen, H. (21960), Reine Rechtslebre, Wien, repr. 2000.

Köhler, W. ( $\left.{ }^{3} 1973\right)$, Intelligenzprüfungen an Menschenaffen, Berlin.

MacCorquodale, K. / Meehl, P. E. (1948), Hypothetical Constructs and Intervening Variables. Psychological Review 55, 95-107.

Mill, J. S. (1969), Collected Works, vol. X, Toronto.

Reid, Th. (1969), Essays on the Active Powers of the Human Mind, ed. B. Brody, Cambridge, Mass.

Rensch, B. (1973), Gedächtnis, Begriffsbildung und Planhandlungen bei Tieren, Berlin.

Saarinen, R. (1994), Weakness of the Will in Medieval Thought, Leiden.

Schlick, M. (1984), Fragen der Ethik, hg. R. Hegselmann, Frankfurt.

Seebaß, G. (1981), Das Problem von Sprache und Denken, Frankfurt.

Seebaß, G. (1993 a), Wollen, Frankfurt.

Seebaß, G. (1993 b), Freiheit und Determinismus, in: Zeitschrift für philosophische Forschung 47, 1-22, 223-245.

Seebaß, G. (1994), Handlungstheoretische Aspekte der Fahrlässigkeit, in: Jabrbuch für Recht und Ethik 2, 375-411.

Seebaß, G. (2001), Kollektive Verantwortung und individuelle Verhaltenskontrolle, in: J. Wieland (Hg.), Die moralische Verantwortung kollektiver Akteure, Heidelberg, 79.99.

Sidgwick, H. (71907), The Methods of Ethics, repr. Indianapolis 1981.

Sigwart, Ch. (1889), Der Begriff des Wollens und sein Verhältnis zum Begriff der Ursache, in: Ch. S., Kleine Schriften, 2. Reihe, Freiburg.

Skinner, B. F. (1953), Science and Human Behavior, New York.

Skinner, B. F. (1974), About Behaviorism, New York.

Staats, A. W. and C. K. (1964), Complex Human Behavior, New York.

Stemmer, P. (2000), Handeln zugunsten anderer, Berlin/New York.

Stemmer, P. (2002), Moralischer Kontraktualismus, in: Zeitschrift für philosophische Forschung 56, 1-21.

Tolman, E. C. (1932), Purposive Behavior in Animals and Men, New York.

Tolman, E. C. (1951), Behavior and Psychological Man, Berkeley.

Tugendhat, E. (1976), Vorlesungen zur Einführung in die Sprachanalytische Philosophie, Frankfurt.

Tugendhat, E. (1984), Probleme der Ethik, Stuttgart.

Tugendhat, E. (1993), Vorlesungen über Ethik, Frankfurt.

Tugendhat, E. (1997), Dialog in Leticia, Frankfurt.

Tugendhat, E. (2001), Aufsätze 1992-2000, Frankfurt.

Wittgenstein, L. (1984), Werkausgabe, Frankfurt. 
Wright, G. H. v. (1963 a), Norm and Action, London.

Wright, G. H. v. (1963 b), The Varieties of Goodness, London.

Wright, G. H. v. (1980), Freedom and Determination, Amsterdam. 